\title{
EL CENTRO POLÍTICO INKA EN EL EXTREMO AUSTRAL DEL TAWANTINSUYU (CHILE CENTRAL)
}

\author{
INKA POLITICAL CENTER IN THE SOUTHERNMOST TIP OF THE \\ TAWANTINSUYU (CENTRAL CHILE)
}

luis Cornejoa \& Miguel SaAvedra ${ }^{\circledR}$

Se presentan los resultados de la investigación arqueológica del sitio inka Palacio de la Real Aduana, ubicado en el centro histórico de la ciudad de Santiago, Chile. Por medio del análisis de su contexto, se interpreta la funcionalidad del asentamiento y el rol que cumplió dentro de la estrategia de dominación inka de la población Aconcagua. Así, se lo define como el centro político del extremo austral del Tawantinsuyu. Además, a partir del estudio de las características tipológicas e iconográficas de la fragmentería alfarera se propone el contexto ideológico de los ceremoniales políticos desarrollados en este lugar y la importancia de la población diaguita en este proceso.

Palabras clave: Inka, Chile central, centro político, Diaguita, Kollasuyu.

These are the results of an archaeological research of the Inka site Palacio de la Real Aduana, located in the historic center of Santiago, Chile. By means of contextual analysis, there is an interpretation of the functionality of this settlement and its role as part of a strategy of Inka domination of the Aconcagua people, which lead to defining this settlement as the political center of the Austral end of the Tawantinsuyu. In addition, the study of the typological and iconographic characteristics of the pottery fragment suggests a possible ideological context of the political ceremonies developed in this place and the importance of the diaguita population in this process.

Keywords: Inka, Central Chile, Political Center, Diaguita, Kollasuyu.

\section{PRESENTACIÓN}

La discusión sobre la ocupación inka en el extremo más austral del Tawantinsuyu, actual territorio del centro de Chile, ha retomado importancia en los últimos años a la luz del cambio en el paradigma hasta hace poco vigente para abordar la manifestación de la presencia estatal en estas lejanas tierras. Las tesis militaristas y economicistas (sic González 2000: 41) han dado paso a una mirada en la que se atribuye mucha más importancia a las herramientas políticas y simbólicas como factor de dominación. Esta trasformación en gran medida se ha desplegado en torno una reinterpretación de uno de los tipos de sitios arqueológicos más conspicuos de la ocupación inka en Chile central, los conjuntos arquitectónicos en reductos de altura, los cuales han pasado de concebirse como fortalezas militares o pukaras (Sanguinetti 1975, Stehberg 1976, Planella et al. 1993) a centros ceremoniales o wakas (Stehberg 2006, Pavlovic et al. 2012, Troncoso et al. 2012). Esta discusión se ha dado en el marco de una reevaluación teórica del concepto mismo de Estado al aplicarlo al Tawantinsuyu, la que se aleja de la férrea imagen ofrecida por la etnohistoria y arqueología tradicional para acercarse a una figura

\footnotetext{
A Luis Cornejo, Departamento de Antropología, Universidad Alberto Hurtado. Almirante Barroso 10, Santiago, Chile, e-mail: lcornejo@uahurtado.cl

B Miguel Saavedra, Lago Yelcho 6028, Puente Alto, Santiago, Chile, e-mail: masvi2@gmail.com
} 
mucho más compleja, que involucra múltiples situaciones diferentes (Ziólkowski 1996, Williams \& D’Altroy 1998, Uribe 1999-2000, Sánchez 2001-2002, Malpass \& Alconini 2010).

El reciente ímpetu de la temática inka en Chile central también ha dado nuevo énfasis a temas que, si bien ya habían sido abordados antes, no se hicieron de manera sistemática. Uno de estos, probablemente el más llamativo, es la eventual existencia de un asentamiento inka de cierta magnitud en el punto mismo donde los conquistadores españoles fundaron en 1541 la actual ciudad de Santiago. Desde las primeras referencias históricas a las actuales propuestas, este establecimiento ha pasado de ser el lugar donde los inkas tuvieron su población (Rosales 1877 [1647]) a una especie de Cuzco provincial que habría marcado incluso la matriz urbana de la ciudad de Santiago (Stehberg \& Sotomayor 2012).

En este contexto, creemos que el reciente estudio arqueológico que hemos realizado en el Palacio de la Real Aduana, construido a finales del siglo XviII, ofrece interesantes evidencias para aportar a la discusión del carácter de la ocupación inka en este lugar y para evaluar la funcionalidad y tipo de asentamiento encontrado en el mismo sitio donde Pedro de Valdivia fundó la actual capital de Chile. Esto se ve potenciado por varios estudios arqueológicos realizados durante distintas obras de construcción en el entorno de la Plaza de Armas (Hotel City, Catedral de Santiago y Metro de Santiago), los que permiten complementar los resultados obtenidos por nuestro trabajo.

\section{ARQUEOLOGÍA DEL PALACIO DE LA REAL ADUANA}

Entender el contexto arqueológico de la ocupación inka en la actual ciudad de Santiago tiene entre sus principales limitaciones la gran cantidad de edificios y otras infraestructuras construidas aquí a partir de mediados del siglo xvi. Cimientos, subterráneos, ductos o pozos han requerido excavaciones que dificultan la conservación de algún segmento de estratigrafía intacto perteneciente a la ocupación inka y de otras registradas anteriormente (Prado \& Barrientos 2011). Sin duda, estas intervenciones han crecido en profundidad y extensión, al punto de que algunos lugares acumulan varias de ellas sucesivas y de gran magnitud.
En consecuencia, el Palacio de la Real Aduana, ubicado sólo a una cuadra de la Plaza de Armas y cuya construcción finalizó hacia 1807 (fig. 1), ofrecía inmejorables posibilidades para identificar depósitos estratigráficos en alguno de sus dos amplios patios (fig. 2). De hecho, en una excavación parcial del Patio Sur realizada en 1986, con motivo de las ampliaciones de las dependencias del Museo Chileno de Arte Precolombino (fig. 2) -institución que tiene su sede en este edificio desde 1981-, si bien no se reconoció una ocupación inka propiamente tal, sí se registró fragmentería de cerámica de tiempos inkas (Botto 1989: fig. 4). Además, se obtuvieron algunos fechados arqueométricos que, aun cuando en el momento se consideraron incompatibles con la información histórica (Botto 1989: 28), a la luz de los análisis cronológicos actuales (Cornejo 2014) resultan compatibles con el momento inka. Desde un carbón asociado a un basural que estaba en la base de la Cuadrícula 1 (sic nivel 9) se obtuvo una fecha de 1283-1622 DC (tabla 1), ${ }^{1}$ mientras que un fragmento de cerámica con pintura roja proveniente del nivel 5 de la Cuadrícula 5 fue fechado por termoluminiscencia en $1520+/-60$ DC. Más aún, un tortero confeccionado en un fragmento de cerámica proveniente del mismo contexto fechado por $\mathrm{C}^{14}$, analizado también por termoluminiscencia dio un resultado de $1280+/-80$ DC.

Sobre la base de estos antecedentes, debido a que ambos patios del edificio serían excavados por completo para la construcción de instalaciones subterráneas del mismo museo y en acuerdo con el Consejo de Monumentos Nacionales, ${ }^{2}$ ejecutamos entre 2010 y 2012 (Saavedra \& Cornejo 2015) un programa de rescate arqueológico que incluyó sondeos y excavaciones extensivas, abarcando un $14,1 \%$ de la superficie de los patios (fig. 2). Además, después de terminadas las excavaciones se procedió a la remoción manual del total de los niveles que presentaban posibles evidencias culturales, tarea que fue monitoreada por arqueólogos y realizada por operarios.

Por desgracia, las excavaciones demostraron una importante cantidad de remociones bajo el suelo, tales como ductos, canaletas y un pozo, pertenecientes a las sucesivas edificaciones coloniales que se levantaron en el lugar (Botto 1989; Saavedra \& Cornejo 2015). Esto es cierto sobre todo en el Patio Sur del edificio, lugar donde, como veremos, se concentra la ocupación inka. Nuestras excavaciones descubrieron allí los cimientos de una estructura hexagonal (Saavedra \& Cornejo 2015: 


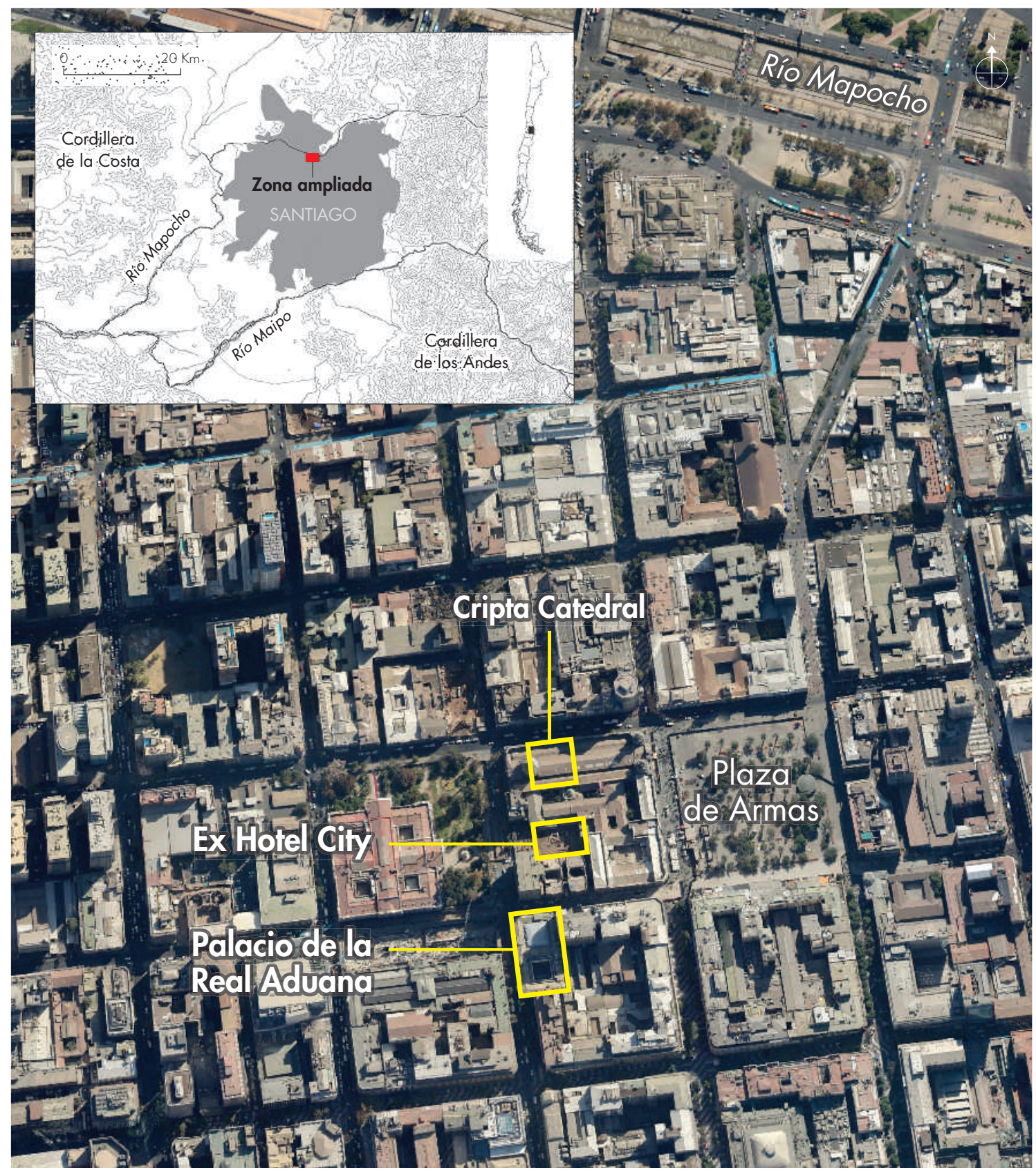

Figura 1. Plano del centro de la ciudad de Santiago donde se ubica el Palacio de la Real Aduana y otros sitios donde se han rescatado evidencias de ocupación inka. Figure 1. Map of the center of the city of Santiago, where the Palacio de la Real Aduana and other sites with evidence of Inka occupation are located.

fig. 12) -probablemente una fuente de la cual no se tiene registro- que afectaron una porción importante del subsuelo.

No obstante, se logró identificar en la base del sector sur de la Unidad 19 (fig. 2) una pequeña área
(0,3 x $1 \mathrm{~m})$ de depósito estratigráfico cuyo contexto corresponde a tiempos inkas, sin alteraciones postdepositacionales. Siguiendo las características de este depósito y su contexto arqueológico se aislaron otros tres perfiles en la base de cuya secuencia estratigráfica 


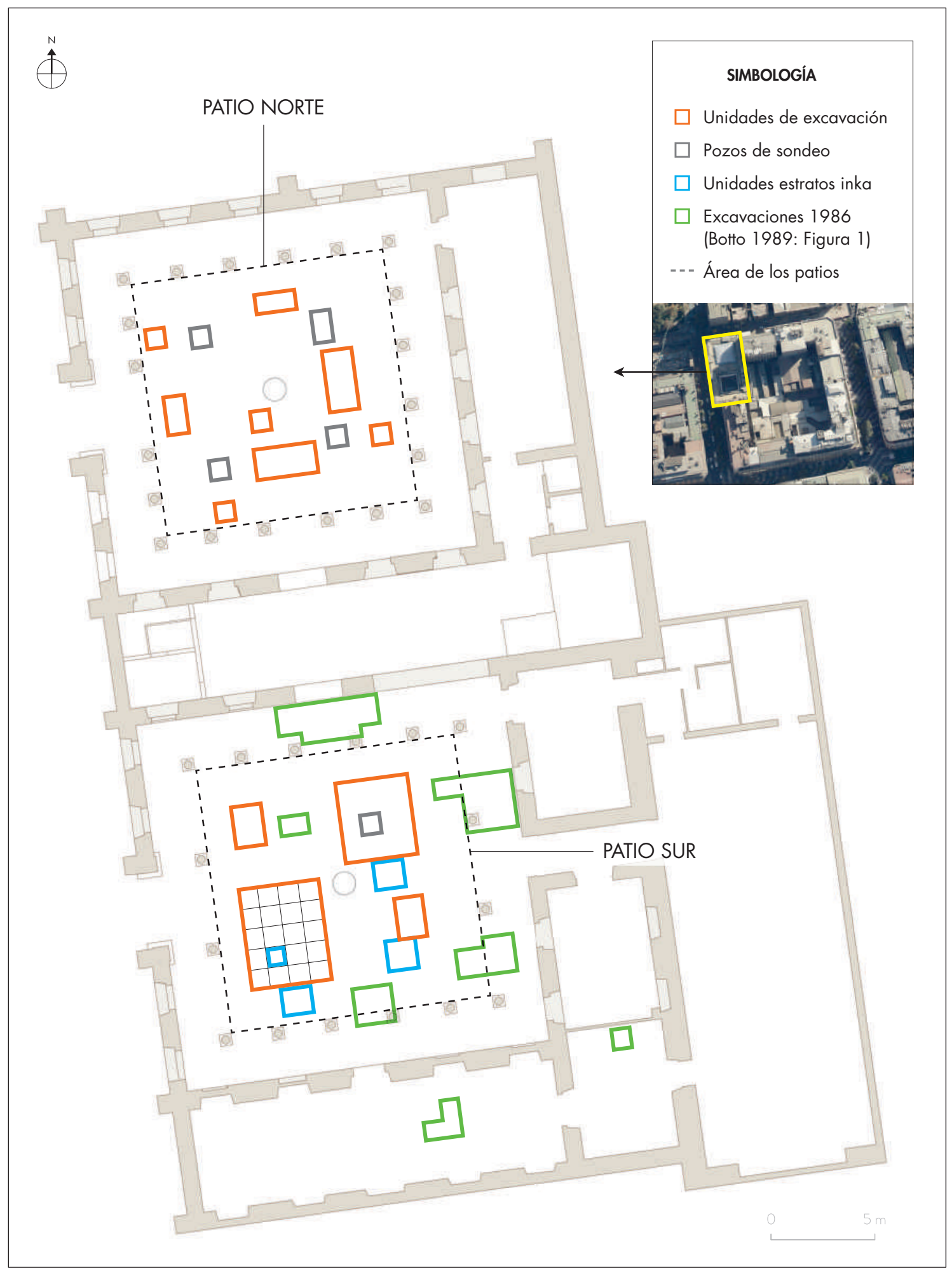

Figura 2. Plano de la primera planta del Palacio de la Real Aduana y de las intervenciones arqueológicas allí realizadas. Figure 2. Map of the first of floor of the Palacio de la Real Aduana including archaeological interventions. 


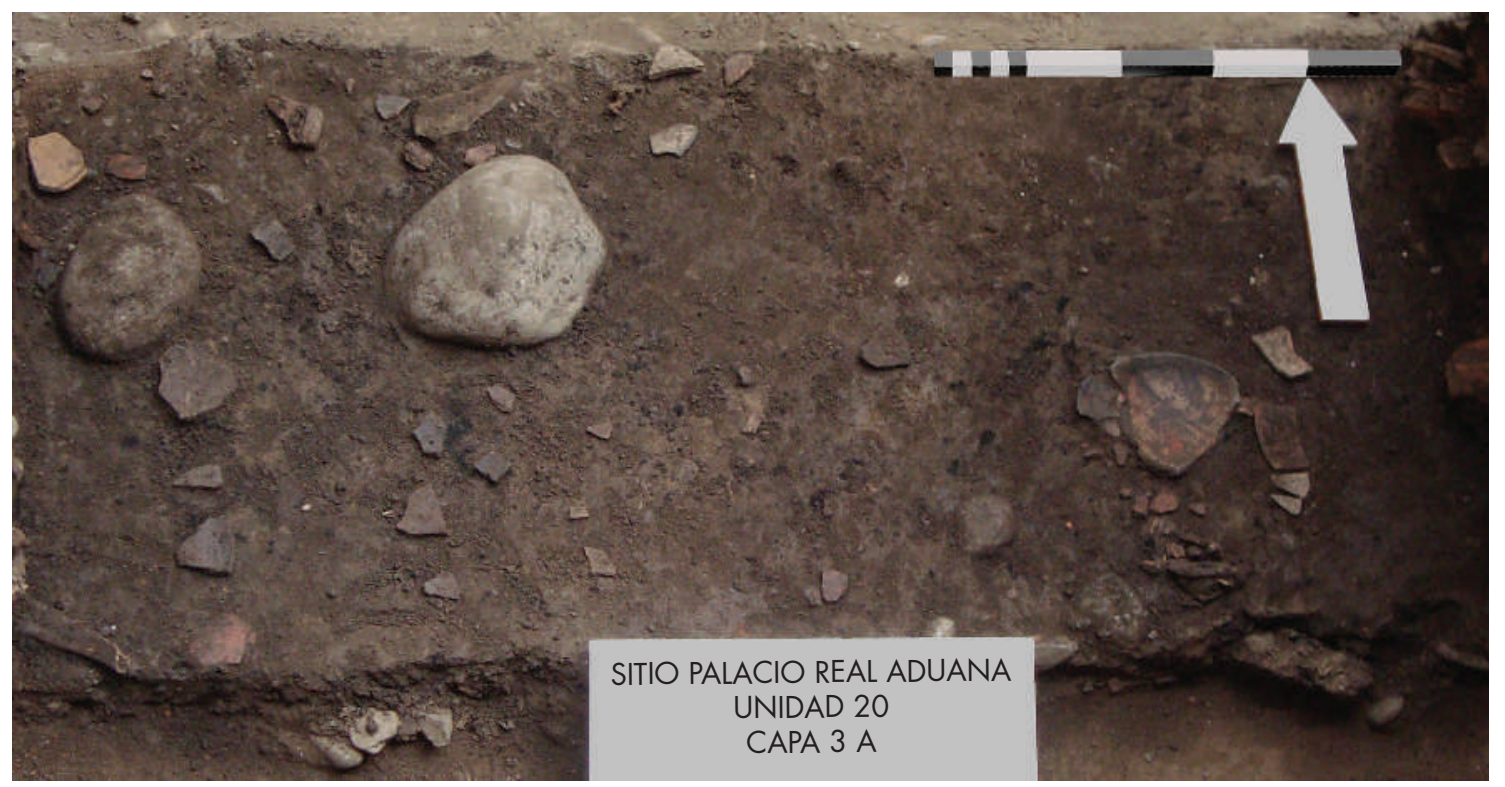

Figura 3. Estrato con basuras de la ocupación inka en proceso de excavación en 2012. Figure 3. Layer with refuse dating from the Inka occupation, from an excavation process of 2012.

Tabla 1. Fechados $\mathrm{C}^{14}$ de la ocupación inka bajo el Palacio de la Real Aduana. Table 1. $C^{14}$ datings of Inka occupation in the site Palacio de la Real Aduana.

\begin{tabular}{|c|c|c|}
\hline MUESTRAS & $\mathrm{EDAD} \mathrm{C}^{14}$ & RANGOS DE FECHAS CALENDÁRICAS CALIBRADAS \\
\hline Unidad 21 / Capa 4b & $430 \pm 30$ & $\begin{array}{l}1443 \text { a } 1512(\mathrm{p}=0,72) \\
1548 \text { a } 1561(\mathrm{p}=0,01) \\
1571 \text { a } 1623(\mathrm{p}=0,25)\end{array}$ \\
\hline Unidad 20 / Capa 3a & $370 \pm 30$ & $\begin{array}{l}1495 \text { a } 1469(\mathrm{p}=0,01) \\
1476 \text { a } 1635(\mathrm{p}=0,99)\end{array}$ \\
\hline Unidad 19N / Capa 2b & $410 \pm 30$ & $\begin{array}{l}1451 \text { a } 1517(\mathrm{p}=0,55) \\
1539 \text { a } 1625(\mathrm{p}=0,45)\end{array}$ \\
\hline Unidad 19N / Capa 3a & $400 \pm 30$ & $\begin{array}{l}1454 \text { a } 1523(\mathrm{p}=0,47) \\
1536 \text { a } 1626(\mathrm{p}=0,52)\end{array}$ \\
\hline $\begin{array}{c}\text { Excavación } 1986 \\
\text { Cuadrícula 1, Nivel } 9\end{array}$ & $590 \pm 90$ & $\begin{array}{l}1283 \text { a } 1511(\mathrm{p}=0,93) \\
1549 \text { a } 1559(\mathrm{p}=0.01) \\
1573 \text { a } 1622(\mathrm{p}=0.06)\end{array}$ \\
\hline Media & $408 \pm 15$ & 1442 a $1486(\mathrm{p}=1,00)$ \\
\hline
\end{tabular}


existían depósitos similares. En torno a estos perfiles se trazaron tres unidades de 1,5 x 1,5 m (fig. 2, unidades 20, 21 y 22) cuyas excavaciones permitieron también aislar segmentos con depósitos propios de la ocupación inka. Esta se manifestaría en un desarrollo sedimentario no mayor de $15 \mathrm{~cm}$ que, considerando las cuatro unidades excavadas, equivale a una superficie de $3,80 \mathrm{~m}^{2}$ distribuida en segmentos delimitados por rasgos históricos que afectaron los depósitos. ${ }^{3}$

El estrato que contiene la ocupación inka se caracteriza por sedimentos limo arcilloso, al igual que la mayor parte de los estratos encontrados en el sitio; asimismo, incluye una gran cantidad de desechos culturales, sobre todo trozos de vasijas, material osteofaunístico y carbón (fig. 3). Esta ocupación se encontraba directamente sobre una pequeña interfase limosa, la cual daba paso a un estrato de cantos rodados propios del relleno aluvial de la cuenca de Santiago. Estos dos últimos cuerpos estratigráficos poseen una pequeña cantidad de restos culturales filtrados desde el piso ocupacional superior.

\section{EL CONTEXTO ARQUEOLÓGICO}

El contexto arqueológico inka registrado en los patios del Palacio de la Real Aduana presenta una serie de características que nos permiten ofrecer una hipótesis respecto al tipo de actividad realizada en el lugar y al tipo de asentamiento en cuestión.

\section{Tipo de depósito}

Una de las principales características de este contexto arqueológico es que corresponde a un depósito de basuras secundarias, es decir, descartadas fuera del lugar en que fueron utilizadas una vez terminada su vida útil (sensu Schiffer 1976, 1983). Esta afirmación se basa en la gran cantidad de fragmentos de piezas de cerámica diferentes que se concentran en un espacio muy reducido. Solo dos de ellos pudieron ser remontados como parte de una misma pieza. A la vez, como se puede observar en la figura 3, la totalidad de los fragmentos de cerámica identificados en este estrato revelaban su eje mayor paralelo al horizonte del suelo. Esto quiere decir que no hubo remoción de los desechos desde el lugar donde se depositaron originalmente (Sunyer et al. 2014), el que correspondería a un piso casi horizontal con una pendiente de solo $0,66 \%$.
Junto al material cultural, sobre todo en el segmento de ocupación inka excavado en la Unidad 20 y en la Unidad 19N (fig. 3), se constató una alta cantidad de carbón, ya sea en la forma de trozos de hasta $1 \mathrm{~cm}$ de diámetro o como particulado fino. El material tiñó los sedimentos limoarcillosos de un color negruzco que permitía diferenciar de manera clara este estrato de los restantes. De hecho, esta fue la característica que sugirió en primera instancia la existencia de esta ocupación en la excavación del cuadrante N de la Unidad 19.

La alta concentración de carbón en estos estratos se asocia a la ya señalada gran presencia de basuras. Si se consideran todos los fragmentos cerámicos que están menos afectos a los procesos tafonómicos y de conservación, la densidad de todos los segmentos con depósitos inkas es de 0,12 fragmentos/litro, considerando solo aquellos de vasijas con rasgos diagnósticos del momento inka (con iconografía trícroma o bícroma y monocromos con escobillado interior).

Si bien no existen muchos antecedentes similares en la región para comparar la concentración de basuras hallada, se puede reconstruir cierta información a partir de los datos publicados para sitios que, dada la evidencia de arquitectura con características diagnósticas, son sin duda ocupaciones inkas (tabla 2). Es así evidente que la densidad de restos de vasijas reportada en este depósito es inusualmente alta. Podríamos definir el lugar como un basural donde se descartó de forma reiterada, en un espacio muy definido y en un tiempo también acotado, restos de vasijas quebradas y el remanente de la limpieza de fogones. Las características de este contexto, en especial su densidad y concentración de vasijas cargadas de iconografía, podría indicar la posibilidad que nos estuviéramos enfrentado a un tipo de depositó arqueológico distinto, como podría ser un lugar de sacrificio ritual de vasijas. Sin embargo, una situación como esta correspondería a un depósito primario, donde además de las características señaladas seria esperable encontrar una alta restaurabilidad de vasijas, cosa que no ocurre.

Todo parece señalar que este basural de tiempos inkas se encontraba a la vista cuando en el lugar se asentaron los primeros españoles en estas tierras, quienes continuaron utilizando el lugar para el mismo propósito. Esto explicaría la alta densidad de restos culturales coloniales, especialmente fragmentos de vasijas y desechos óseos de animales de granja, que están mezclados con los restos inkas y tienen las mismas características depositacionales que ellos (diversidad y horizontalidad). De hecho, en 
Tabla 2. Estimación de densidad de fragmentos de cerámica diagnósticos de sitios inkaicos de Chile central. Table 2. Estimated density of diagnostic pottery fragments of Inka sites in Central Chile.

\begin{tabular}{c|c|c|c|c}
\hline SITIO & TIPO & UBICACIÓN & $\begin{array}{c}\text { DENSIDAD, FRAGMENTOS, } \\
\text { DIAGNÓ STICOS INKA }\end{array}$ & REFERENCIA \\
\hline Laguna del Indio & $\begin{array}{c}\text { Conjunto de } \\
\text { estructuras }\end{array}$ & Cordillera del río Maipo & $0,0 /$ litro & Stehberg $2013^{*}$ \\
\hline Cerro El Peral & $\begin{array}{c}\text { Estructura en } \\
\text { avistadero }\end{array}$ & Cuenca de Santiago 2006 \\
\hline $\begin{array}{c}\text { Cerro Grande } \\
\text { de la Compañía }\end{array}$ & $\begin{array}{c}\text { Pukara-Waka } \\
\text { Cerro Chena }\end{array}$ & Cuenca de Rancagua & $0,0001 /$ litro & Planella et al. 2004 \\
\hline Ex Hotel City & Basuras & Cuenca de Santiago & $0,0007 /$ litro & Stehberg $1976^{* *}$ \\
\hline Cripta Catedral & Basuras & Cuenca de Santiago & $0,022 /$ litro & Galarce et al. 2014 \\
\hline
\end{tabular}

${ }^{*}$ En estos casos el cálculo de la densidad no es definitivo, ya que en la publicación faltaban algunos datos del tamaño de las unidades excavadas. ${ }^{*}$ El cálculo es una aproximación a partir del largo total de los muros excavados, la media del ancho señalada para ellos y su profundidad. ${ }^{\star * *}$ Dado que los fragmentos diagnósticos no se asociaron a un rasgo específico, se calculó la densidad considerando la cantidad de fragmentos y la superficie total excavada.

Tabla 3. Proporción de clases de materiales arqueológicos presentes en los estratos inkas. Table 3. Proportion of classes of archeological materials from Inka strata.

\begin{tabular}{c|c|c|c} 
TIPO DE MATERIAL & No & $\%$ & DENSIDAD (UNIDADES / LITRO) \\
\hline Cerámica & 480 & 32,0 & 0,015 \\
\hline Lítico & 7 & 0,5 & 0,019 \\
\hline Metal & 9 & 0,6 & 2,148 \\
\hline Osteofaunístico & 1002 & 66,9 & 3,21 \\
\hline Total & 1498 & & 3
\end{tabular}

las excavaciones de 1986, como ya se dijo, se identificó en la base de la Cuadrícula 1, muy cercana a nuestras Unidades 20 y 21 (fig. 2), un importante basural (fig. 4), compuesto en gran medida por restos óseos de animales de granja europeos (Botto 1989: 16).

\section{Contextos histórico-culturales}

La información arqueométrica para ubicar en el tiempo la ocupación inka contempla cuatro fechas de $\mathrm{C}^{14}$ obtenidas desde algunos de los segmentos excavados por nosotros, las cuales se pueden equiparar con cierto margen de seguridad a la ya referida muestra reportada por Botto (1989). Dichos datos sitúan el evento inka en un margen que va desde tiempos prehispánicos al inicio del Período Colonial (tabla 1). No obstante, cuando se promedian las probabilidades acumuladas ya calibradas del conjunto ${ }^{4}$ se obtiene un rango de 1443 a $1489(p=0,99),{ }^{5}$ correspondiente a pleno Período Inka de Chile central (Cornejo 2014), previo a la fundación española de la ciudad de Santiago en 1541.

Estas evidencias indican claridad que la depositación de carbones en los estratos ocurrió en tiempos inkas, aunque el contexto arqueológico de los estratos 
Tabla 4. Proporción de tipos identificados en los fragmentos de cerámica presentes en los estratos inkas. Table 4. Proportion of identified types in pottery fragments from Inka strata.

\begin{tabular}{|c|c|c|c|c|}
\hline & TIPO* & $\mathrm{N}^{\circ}$ & $\%$ & DENSIDAD (FRAGMENTOS / LITRO) \\
\hline \multirow{2}{*}{ 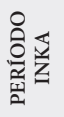 } & Período Inka con iconografía diagnóstica & 16 & 3,33 & 0,03 \\
\hline & Monocromo Escobillado & 41 & 8,54 & 0,09 \\
\hline \multirow{7}{*}{ 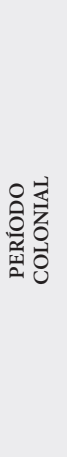 } & Brillante Pulida muy delgada & 7 & 1,46 & 0,02 \\
\hline & Esmaltado & 4 & 0,83 & 0,01 \\
\hline & Grandes Contenedores Torno & 15 & 3,13 & 0,03 \\
\hline & Loza & 1 & 0,21 & 0,00 \\
\hline & Mayólica Panameña & 7 & 1,46 & 0,02 \\
\hline & Mayólicas & 11 & 2,29 & 0,02 \\
\hline & Vidriado & 4 & 0,83 & 0,01 \\
\hline \multirow{3}{*}{ 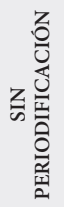 } & Monocromo Indígena & 245 & 51,04 & 0,53 \\
\hline & Rojo pintados n/i & 124 & 25,83 & 0,27 \\
\hline & Antiplástico Vegetal & 5 & 1,04 & 0,01 \\
\hline
\end{tabular}

*Clasificación tipológica realizada por Baudet y Baeza (2013).

incluye tanto materiales de evidente filiación inka con otros de filiación europea, así como otros más difíciles de asignar con seguridad a determinado período histórico (tabla 3). Como lo detallaremos, son de filiación inka fragmentos de vasijas con iconografías trícromas o bícromas o fragmentos monocromos cuyo interior presenta un característico alisamiento escobillado, provenientes de cuencos, jarras y cántaros bastante conocidos para la región (Mostny 1947, Vásquez 1994, Cornejo 2001a, Sanhueza 2001, Cantarutti \& Mera 2002, Correa et al. 2008, Fuenzalida 2015). Por su parte, el contexto lítico (Contreras 2013), con excepción de la mano de moler (tabla 4), podría asignarse sin problemas a tiempos inkas, ya que las funciones que por lo general representan (cepillar, raspar, cortar o perforar) son cubiertas por los españoles que ocuparon el lugar con objetos de metal y no tenemos evidencias de otra ocupación prehispánica allí.

El contexto colonial español rescatado desde estos mismos niveles, especialmente desde los centímetros superiores, incluye metales (Latorre 2013), siete clavos de hierro forjados de forma manual, una barra de hierro irregular y un tubo de adorno en aleación de cobre, todos ellos hispánicos. Una situación parecida ocurre con el contexto osteofaunístico (López 2013). Si se consideran las piezas en las que se determinaron especies o familias, aquel está dominado por animales de granja europeos (cerdos, cabras, ovejas y gallinas, que constituyen el $83,8 \%$ de las piezas identificadas), mientras que no hay ninguna pieza identificada de camélidos americanos u otras especies de animales asignables a la ocupación inka. Del mismo modo, el contexto cerámico de este período (Baudet \& Baeza 2013) está integrado por fragmentos de vasijas mayólicas, esmaltadas o del tipo brillante delgado muy pulido o de otras que presentan evidencias de confección a través de torno.

El contexto cerámico, sin embargo, está compuesto en su mayor parte por fragmentos de vasijas cuya filiación cronológica cultural no pudo determinarse de modo preciso. Como se puede observar en la tabla 4, estos corresponden a más del 75\% de los fragmentos y se definen como monocromos de tradición indígena o mestiza y 


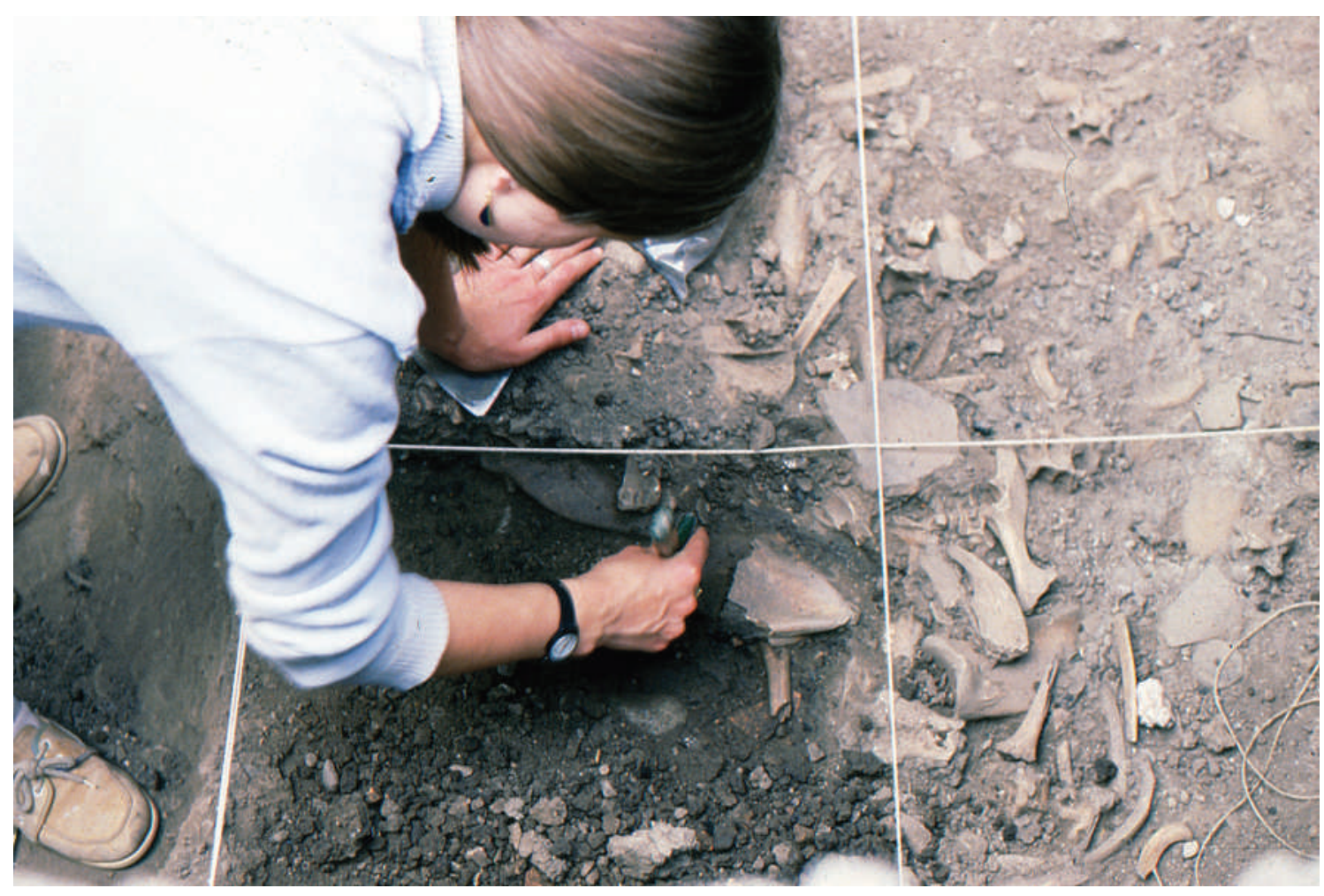

Figura 4. Basurero de tiempos coloniales depositado sobre la ocupación inka (fotografía del momento de su excavación en 1986). Figure 4. Refuse from the Colonial period deposited above the Inka occupation layer by the moment of its excavation in 1986.

rojos pintados (Baudet \& Baeza 2013). Una porción debe corresponder a las partes de vasijas del Período Inka cuya iconografía característica suele encontrarse solo en un segmento de la pieza y/o a vasijas no decoradas. Seguramente, esta fue una proporción importante de las piezas utilizadas aquí en tiempos inkas. Sin embargo, es también probable que muchos de estos fragmentos sean restos de vasijas hechas por indígenas en tiempos coloniales, quienes habrían continuado con los estilos tecnológicos propios de la tradición local preuropea. De hecho, la presencia de estos tipos cerámicos es muy frecuente aún (tipo Monocromo de Tradición Indígena o Mestiza $=38,2 \%$; Rojo Pintado $=10,8 \%$ ) en otros estratos del sitio que, por su posición estratigráfica, deben ser de tiempos coloniales, como el estrato 2 de la unidad 15. Cabe señalar que rasgos tecnológicos característicos de la tradición precolombina, tal como la construcción de las vasijas por rodetes, fueron comunes hasta hace pocas décadas en Pomaire, una aldea de alfareras de origen mestizo ubicada a $51 \mathrm{~km}$ al poniente del centro de Santiago (Valdés \& Matta 1986).
De esta manera, podemos segregar un contexto arqueológico propio del asentamiento inka que existió en este lugar, compuesto por una densidad inusualmente alta de restos cerámicos de vasijas asignables a este momento de acuerdo a la tipología de su iconografía, formas o características de manufacturación. Llamaremos a estos restos "fragmentos diagnósticos", considerando que son efectivamente únicos de la ocupación inka en Chile central. Junto con ellos, se incluye una importante cantidad de restos de carbón que no forman fogones, sino que se incorporaron en la basura. De hecho, una proporción no menor de los fragmentos cerámicos $(18,5 \%)$ ostenta señales de carbonización (fracturas carbonizadas), lo que indicaría que fueron depositados aquí mientras las cenizas y carbones aún estaban incandescentes, cosa que no ocurre con los fragmentos de vasijas coloniales españolas.

\section{La alfarería de tiempo inkas}

A partir de la caracterización del contexto arqueológico de tiempos inkas antes reseñada es posible incluir en 
nuestros análisis los fragmentos de alfarería diagnósticos inkas provenientes de las otras unidades de excavación realizadas en los patios del Palacio de la Real Aduana. En ellas, si bien no se logró identificar un estrato inka propiamente tal (debido al alto grado de intervención posterior del subsuelo), en su mayoría sí se rescataron fragmentos diagnósticos de la ocupación inka desde casi todos los estratos excavados. Así, la muestra llegó a un total de 421 fragmentos de distintos tipos de vasijas.

Los fragmentos fueron identificados por la presencia de motivos geométricos que siguen principios de simetría (Washburn 1983) relacionados en su mayor parte con patrones iconográficos de la cultura Diaguita (Cornejo 1989, 2003; González 2001, 2013). Esta sociedad se desarrolló en momentos preinkas en los valles semiáridos, localizados entre 300 y $600 \mathrm{~km}$ al norte de la cuenca del río Mapocho (Latcham 1928; Cornely 1956, 1962; Ampuero 1978), y al parecer jugó un papel central en la expansión inka hacia los valles de Aconcagua, Mapocho, Maipo y Cachapoal (González 2000, Cornejo 2001b, Sánchez 2004). Junto con esto, la evidencia del engobe blanco como base para motivos pintados en negro y/o rojo, rasgo también diaguita y que no se observa en la alfarería preinka local del valle del Mapocho, se ha utilizado como elemento discriminador en aquellos fragmentos cuyos motivos pintados no se alcanzan a distinguir. Por último, en algunos pocos casos se identificaron patrones iconográficos de filiación inka (Fernández Baca 1971).

Del total, 412 fragmentos exhiben particularidades que nos han permitido realizar una clasificación taxonómica de base politética (Cornejo 2000) dirigida a caracterizar el conjunto de vasijas descartadas en el sitio. Esta clasificación se ha basado en la forma general de las piezas inferida a partir de los fragmentos, sus tamaños y ciertas características iconográficas, todo lo cual tuvo como base el conocimiento que hoy existe sobre la alfarería de tiempos inkas de Chile central (Vásquez 1994; Sanhueza 2001; Cantarutti \& Mera 2002, 2004; Correa et al. 2008; González 2013; Fuenzalida 2015) y la de áreas vecinas (p.e., Calderari \& Williams 1991; Bray 2003, 2004).

Dicha taxonomía tiene como primer argumento clasificatorio la segregación de aquellos fragmentos cuya base para los motivos es roja o del color de la pasta, respecto de aquellos cuya base es blanca. A partir de ahí se siguen argumentos específicos para cada rama y se identifican un total de nueve tipos diferentes, cuyos detalles cuantitativos se encuentran en la tabla 5 .
- Tipo 1. Vasijas abiertas de cuerpo semielíptico de paredes altas, llamadas tradicionalmente pucos (Vásquez 1994: 7; Correa et al. 2008: 152), forma propia de la tradición Aconcagua (Sánchez \& Massone 1995). En su interior se hallan motivos pintados en negro que forman patrones de origen diaguita -como el zigzag (Cornejo 1989: 67)-, dispuestos sobre engobe rojo a rojo anaranjado (fig. 5a). Dada la ausencia de características inkas, podríamos asignarla al tipo Local de Fase Inka propuesto por Cantarutti y Mera (2002).

- Tipo 2. Vasijas abiertas que no ha sido posible definir con mayor precisión debido al pequeño tamaño de los fragmentos. Su superficie exterior e interior está engobada en rojo oscuro, mientras que en la parte interior presentan fragmentos de motivos lineales pintados en blanco y, en algunos casos, negro (fig. $5 b)$. No tenemos absoluta certeza de su adscripción, aunque los diseños lineales podrían corresponder a segmentos de patrones diaguitas.

- Tipo 3. Vasijas cerradas en forma de jarras con cuellos cortos y cuerpo globular, que no tiene antecedentes aconcaguas, diaguitas o inkas. Se rescataron ocho asas cinta de sección ovoide que, considerando el color de la superficie y de los motivos pintados, asumimos que corresponden a estos jarros. Las vasijas muestran en la superficie exterior un engobe rojo anaranjado sobre el cual se observan motivos pintados en negro que forman patrones de origen diaguita (fig. 5c), especialmente el patrón zigzag (Cornejo 1989: 66). En términos de tratamiento de superficie y configuración de los motivos, estas jarras serían muy similares a los pucos del tipo 1 , aunque las paredes serían de un espesor un tanto menor (tabla 5) y también asignables al tipo Local de Fase Inka (Cantarutti \& Mera 2002).

- Tipo 4. Representado por un solo fragmento, correspondería a una vasija cerrada de la cual solo se conserva parte del cuerpo, tal vez un jarro. Su principal característica sería un motivo pintado en rojo sobre el color de la pasta (fig. 5d), motivo parece corresponder a un triángulo escalerado que forma parte del patrón zigzag diaguita (Cornejo 1989: 67).

- Tipo 5. Vasijas abiertas de cuerpo semielíptico de paredes bajas que corresponderían a la categoría inka de chua (Vásquez 1994, Bray 2003). Presentan engobe blanco en el interior y el exterior, y sobre él 
Tabla 5. Características cuantitativas de los tipos diagnósticos de tiempos inkas identificados. Table 5. Quantitative features of identified diagnostic types from Inka-period.

\begin{tabular}{|c|c|c|c|c|}
\hline TIPO & $\mathrm{N}^{\circ}$ FRAGMENTOS & Nº MÍNIMO DE VASIJAS & $\bar{X}$ ESPESOR PAREDES & $s^{2}$ ESPESOR PAREDES \\
\hline 1 & 36 & 11 & 5,00 & 0,83 \\
\hline 2 & 6 & 2 & 4,07 & * \\
\hline 3 & 47 & 11 & 4,53 & 0,57 \\
\hline 4 & 1 & 1 & * & * \\
\hline 5 & 9 & 8 & 5,63 & 5,68 \\
\hline 6 & 9 & 9 & 5,03 & 0,44 \\
\hline 7 & 94 & 51 & 5,26 & 1,10 \\
\hline $7 a$ & 30 & 20 & 5,36 & 0,76 \\
\hline $7 \mathrm{~b}$ & 27 & 25 & 5,16 & 0,41 \\
\hline 8 & 117 & 34 & 5,39 & 27,5 \\
\hline 9 & 33 & 6 & 7,04 & 0,83 \\
\hline
\end{tabular}

se disponen motivos en negro y/o rojo, ya sea en el exterior o en el interior (fig. 6a). Si bien el tamaño de los fragmentos no permite distinguir con claridad claramente los patrones de los motivos, se aprecian elementos como triángulos escalerados, parte del patrón zigzag (Cornejo 1989: 67), y laberinto (González 2013: 153), ambos de filiación diaguita. Correspondería al tipo Inka Mixto de Cantarutti y Mera (2002).

- Tipo 6. Vasijas abiertas semielípticas de paredes bajas que corresponderían a la categoría inka de chua (Vásquez 1994, Bray 2003). En su exterior ostentan una pequeña franja de engobe blanco, en alguno casi delimitado por una línea negra, mientras que en su interior se observa engobe rojo (fig. 6b). Dada su forma y la ausencia de motivos, asumimos que se trata de chua sin iconografía, asignable también al tipo Inka Mixto de Cantarutti y Mera (2002).

- Tipo 7. Vasijas abiertas de cuerpo semielíptico. En su exterior se encuentra engobado rojo o solo pulido o alisado; en su interior, engobe blanco sobre el cual se han dispuesto motivos en negro y/o rojo. Estos presentan patrones de origen diaguita, como laberintos (González 2013: 153) o zigzag (Cornejo 1989: 67), y otros diaguita-inka, como doble reflexión especular (González 1998, 2013: 203). Dado que a partir de los fragmentos de estas piezas solo es posible identificar la forma específica de la pieza en los bordes, se separó este tipo en dos variantes (fig. 7 a y b) identificadas solo por esa parte del cuerpo.

- Tipo 7a. Pucos (Vásquez 1994: 7, Correa et al. 2008: 152) que corresponderían al tipo Local de Fase Inka de Cantarutti y Mera (2002).

- Tipo 7b. Chua (Vásquez 1994: 7), que corresponderían al tipo Inka Mixto de Cantarutti y Mera (2002). Muchas piezas tienen el borde plano -diferente del redondo, propio de los pucos- y líneas pintadas de color rojo y/o negro.

- Tipo 8. Vasijas cerradas en forma de jarras, con cuellos cortos, cuerpo globular y paredes delgadas; consi- 


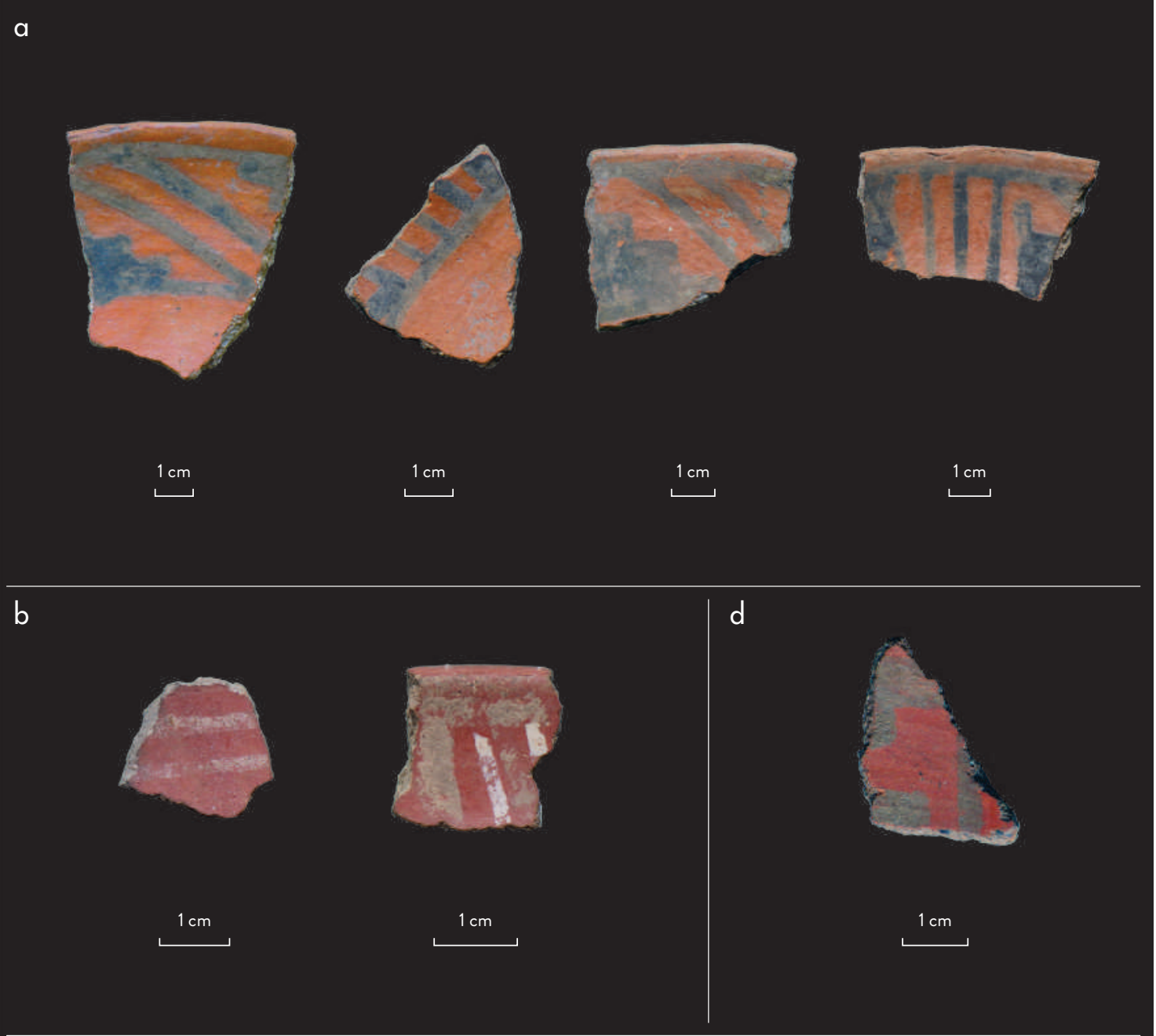

c
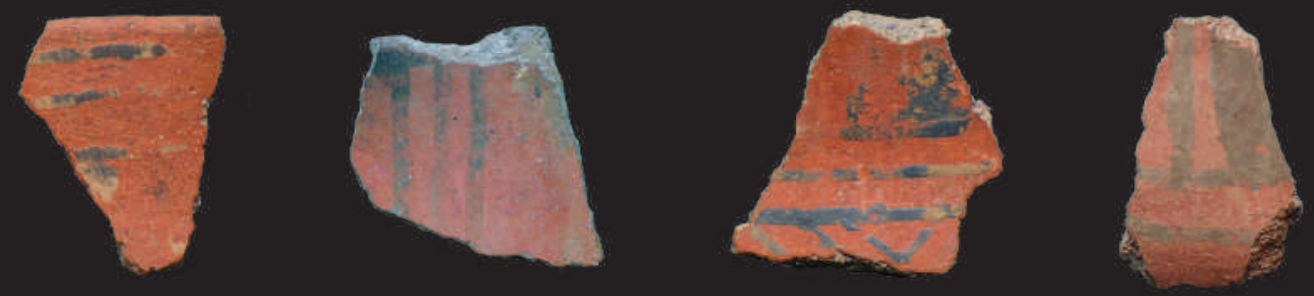

$1 \mathrm{~cm}$

$1 \mathrm{~cm}$

$1 \mathrm{~cm}$

$1 \mathrm{~cm}$

Figura 5. Ejemplos de fragmentos de los tipos identificados: a) tipo 1; b) tipo 2; c) tipo 3; d) tipo 4. Figure 5. Examples of the fragments of identified types: $\boldsymbol{a}$ ) type $1 ; \boldsymbol{b})$ type 2; c) type 3; d) type 4. 


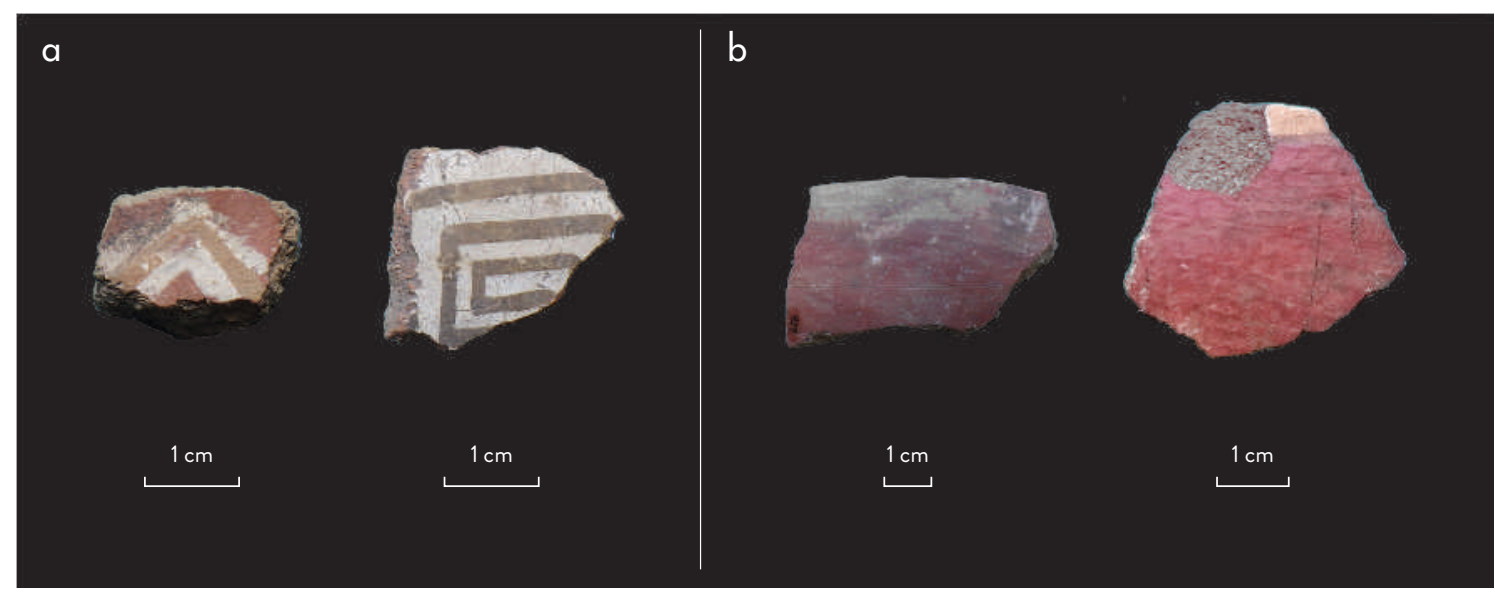

Figura 6. Ejemplos de fragmentos de los tipos identificados: a) tipo 5; b) tipo 6. Figure 6. Examples of the fragments of identified types: a) type 5; b) type 6 .

derando la varianza $\left(\mathrm{s}^{2}\right)$ en el espesor de las paredes (tabla 5), habría una alta variedad de tamaños. No se rescató ningún asa que pueda ser asignada a esta forma, aunque dado el contexto de piezas completas conocidas (p.e., Latcham 1928, Quevedo et al. 1999, Baudet 2008, Fuenzalida 2013), debiera haber al menos una. Debido al tamaño de los fragmentos no fue posible discriminar con precisión la forma de las piezas, algunas de las cuales podrían corresponder a aysana y otras a jarras del estilo Viluco comunes en Chile central y la región trasandina de Cuyo (Lagiglia 1978, Prieto \& Chiavazza 2009). Esta última forma no tiene antecedentes locales ni Inka. El interior de las piezas presenta en algunos casos engobe rojo y en otros solo alisado o pulido, mientras que en el exterior, sobre todo en su mitad superior, se halla engobado de color blanco (fig. 8). Este último sirve de base para motivos en negro y/o rojo, especialmente patrones zigzag diaguita (Cornejo 1989: 67) y algunos de origen inka, tales como rombos en hileras o espigas (González 2013: 219, 207). Las posibles aysana debieran ser clasificadas en el tipo Inka Mixto y las jarras, si bien ya han sido definidas como el tipo Viluco (Lagiglia 1978, Prieto \& Chiavazza 2009), responderían más bien a la lógica del tipo Local de Fase Inka de Cantarutti y Mera (2002).

- Tipo 9. Vasijas cerradas en forma de jarros o cántaros de paredes gruesas. Algunos de ellos corresponderían maka, forma inka que es frecuente en Chile central (Sanhueza 2001), aunque dado el tamaño de la fragmen- tería y a que estamos trabajando solo con el segmento decorado, no podemos segregarlos con precisión. En el exterior, sobre una base de engobe blanco se pintaron motivos en negros y/o rojos (fig. 9), pero el tamaño de los fragmentos y de los motivos dificulta distinguir patrones, aunque se observan rombos en hilera de origen inka (González 2013: 219) y partes de patrones zigzag diaguita (Cornejo 1989: 67) que se podrían atribuir al tipo Inka Mixto de Cantarutti y Mera (2002). En general, estos fragmentos presentan sus superficies exteriores más erosionadas, por lo cual es presumible pensar que estas piezas tuvieron una vida útil más larga o fueron más trasportadas que el resto de las vasijas de este contexto.

A las partes que no exhiben motivos de las piezas de este último tipo correspondería una gran cantidad de fragmentos alisados o con engobe rojo exterior y con un característico alisado por escobillado interior que, como se señaló, también forma parte de este contexto (fig. 10). Sin embargo, considerando los antecedentes de piezas completas conocidas en cementerios de tiempos inkas, otra parte de estos fragmentos debiera corresponder a piezas cerradas, como jarros, maka e incluso ollas de tiempos inkas sin iconografía. Esta situación dificulta la definición de un tipo para este conjunto, pero se debe considerar que es la categoría cerámica de la ocupación inka más frecuente en el sitio (tabla 4).

A partir de esta clasificación se realizó un análisis comparativo, fragmento por fragmento, de una parte específica del cuerpo de las piezas, ya sea bordes, 


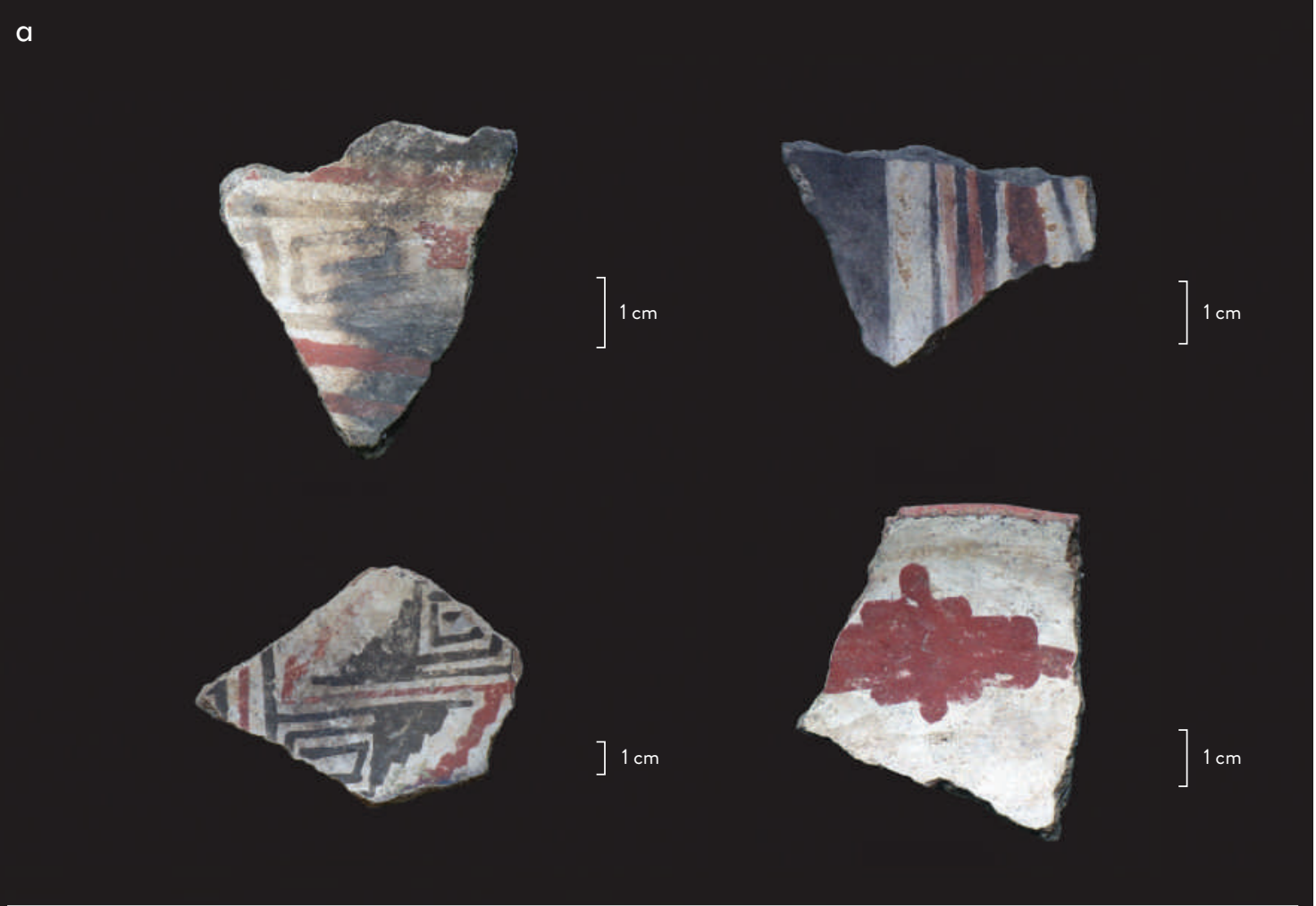

b
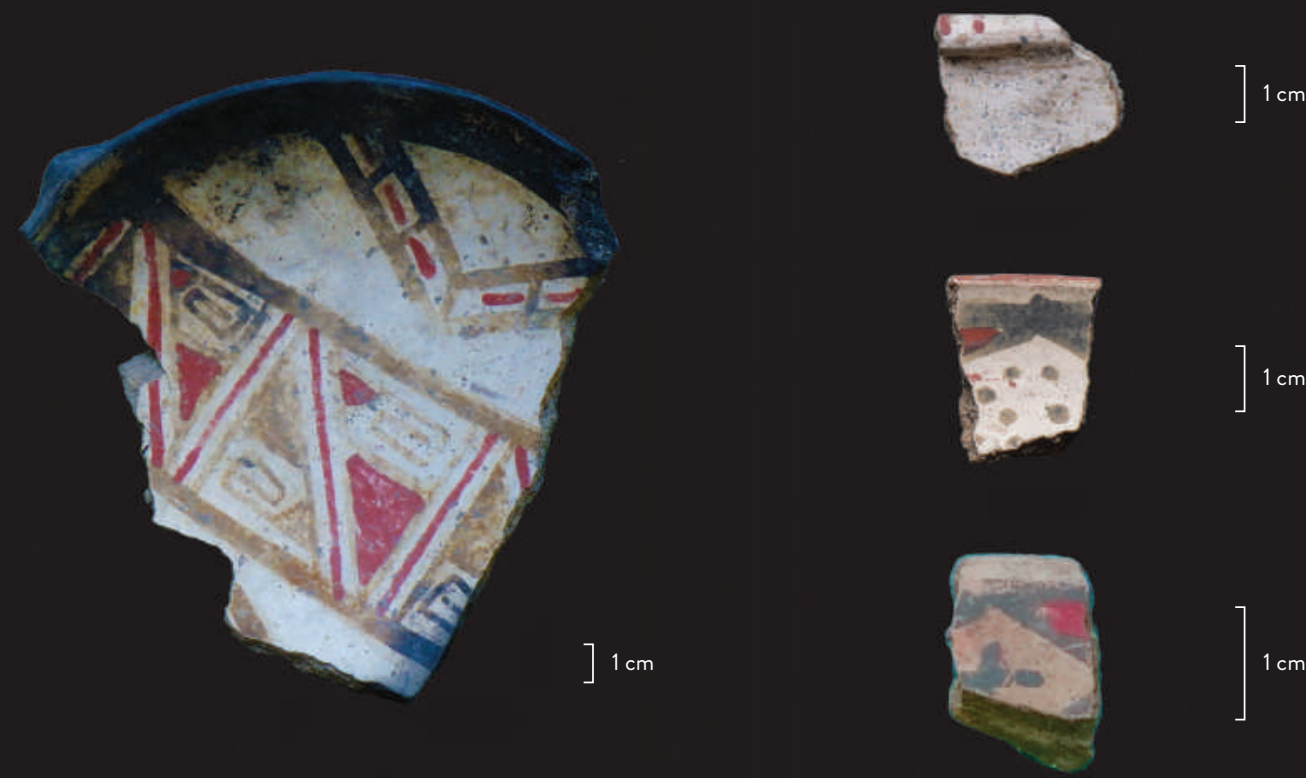


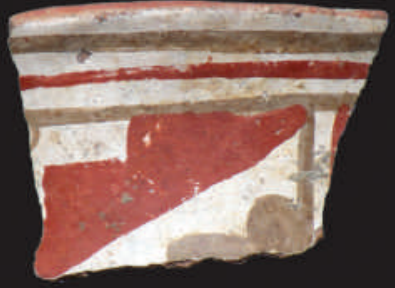

$1 \mathrm{~cm}$

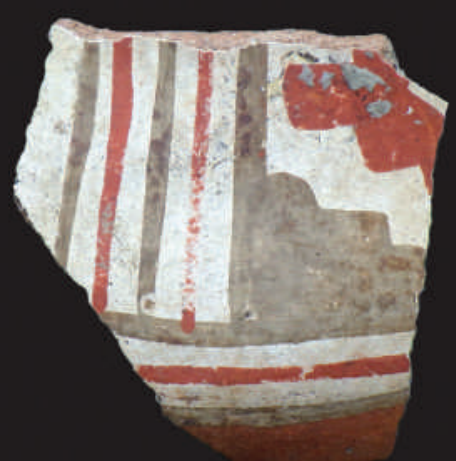

$1 \mathrm{~cm}$

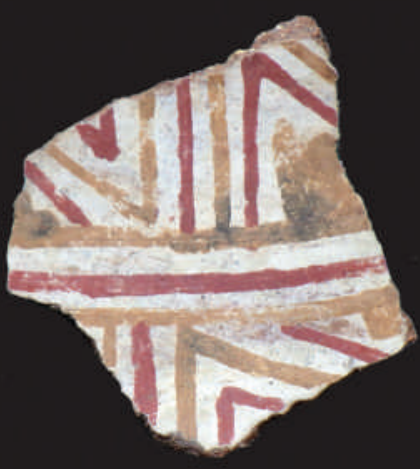

$1 \mathrm{~cm}$

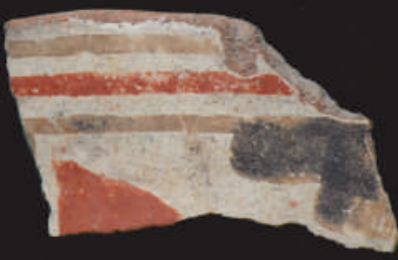

$1 \mathrm{~cm}$

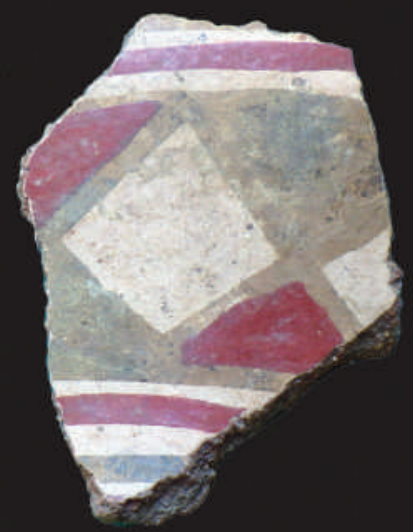

$1 \mathrm{~cm}$

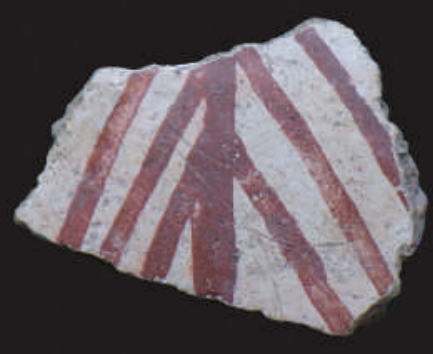

$1 \mathrm{~cm}$

Figura 8. Ejemplos de fragmentos del tipo 8. Figure 8. Examples of type 8 fragments. 


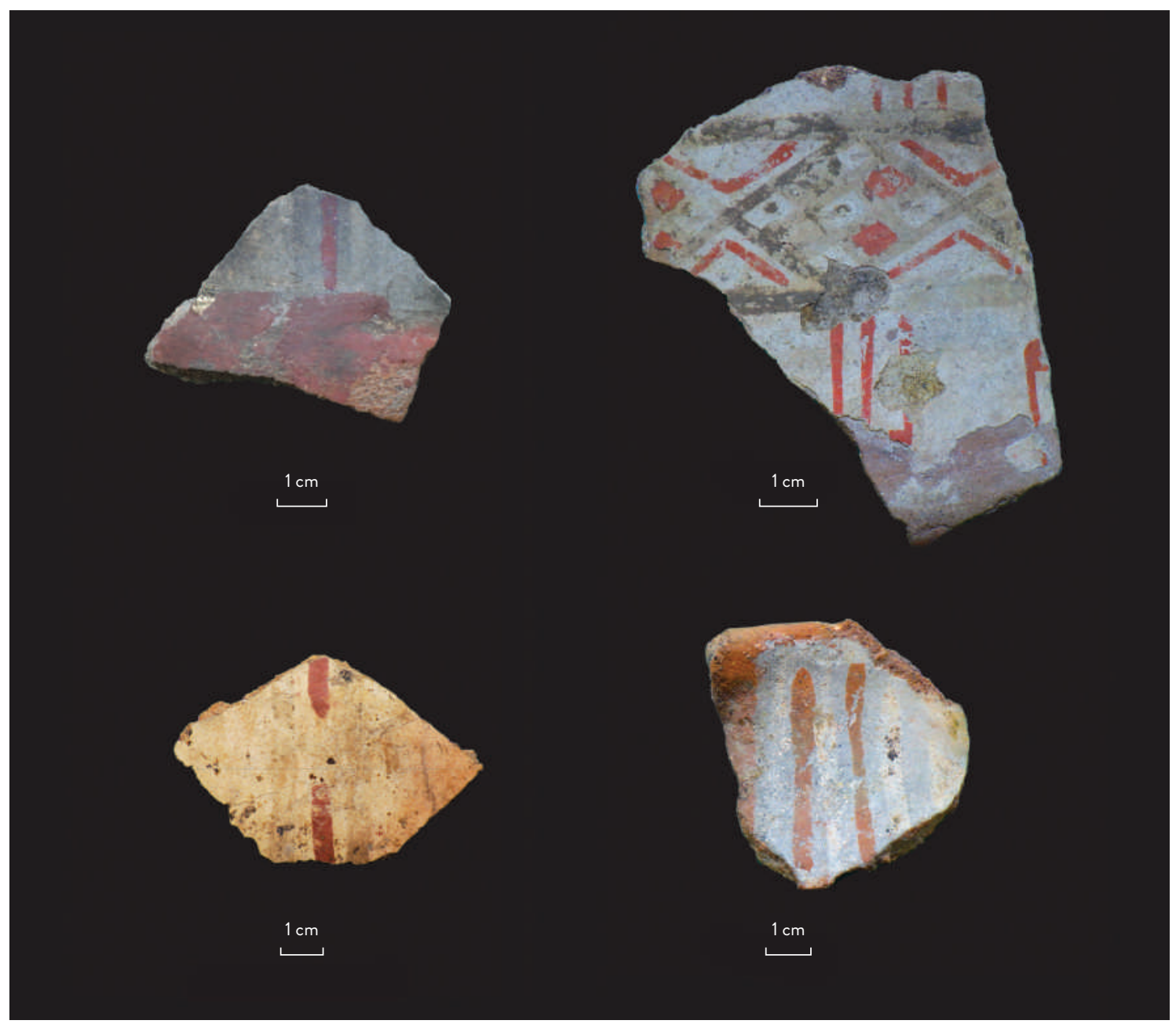

Figura 9. Ejemplos de fragmentos del tipo 9. Figure 9. Examples of type 9 fragments.

cuerpos o cuellos, en cada uno de los tipos definidos. Utilizando la forma inferida de la pieza, su tamaño, color, tratamiento de superficie y motivos pintados, se contabilizó para cada tipo el número mínimo de vasijas (tabla 5). Con esta metodología, se estimó un número mínimo de 133 vasijas, lo que considerando el tamaño del sitio y la muestra excavada, permitiría extrapolar que en este lugar se habrían descartado cerca de 700 vasijas con motivos pintados y, seguramente, una proporción mucho mayor de vasijas sin ellos durante los casi 50 años que pudo haber sido utilizado este lugar en tiempos inkas, de acuerdo a la cronología absoluta. Este conjunto daría cuenta de utensilios usados para beber y comer (Vásquez 1994, Bray 2003), en un contexto en que una gran cantidad de personas participarían de lo que Dillehey (2003) llamó banquetes políticos, una de las agencias centrales de la política de la dominación inka.

\section{Distribución espacial del contexto}

El contexto inka que hemos reseñado, más allá de las áreas donde se logró encontrar segmento de estratos no alterados de tiempos inkas, tiene una distribución en el sitio que, así como en otros sitios cercanos, es necesario resaltar. En la escala más pequeña resulta destacable que los dos sectores separados donde realizamos excavaciones en el Palacio de la Real Aduana, los Patios Sur y Norte, presentan diferencias en la densidad de materiales recuperados: mientras el Patio Sur alcanza una densidad 


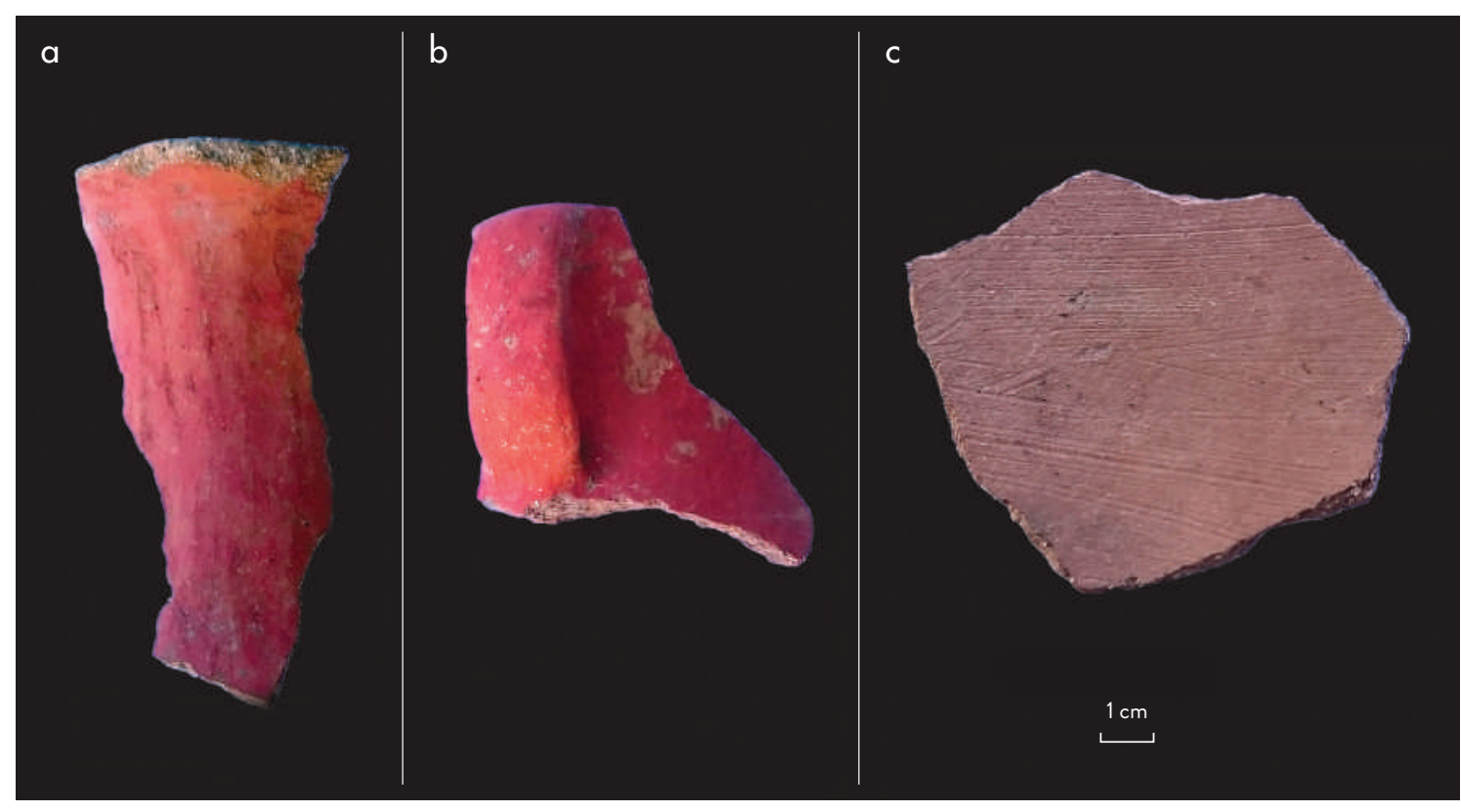

Figura 10. Ejemplos de fragmentos sin iconografía de la ocupación inka: a) trozo de cuello y borde de "maka”; b) trozo de cuello y borde con asa de jarro; c) característico alisado escobillado de las vasijas cerradas de tiempos inkas de Chile central. Figure 10. Examples of fragments without iconography from the Inka occupation period: a) piece of neck and edge of a "maka"; $b$ ) piece of neck and edge with vase handle; c) polish by brushing characteristic of vases of the Inka period in Central Chile.

de 0,07 fragmentos diagnósticos/litro, el Patio Norte alcanza un valor inferior (0,053 fragmentos/litro). ${ }^{6}$

A su vez, es importante señalar que la mayor parte de las piezas rescatadas en este lugar $(n=246,58,4 \%)$ vienen de la unidad 19 del Patio Sur (fig. 2), la que alcanzaría una densidad de 0,12 fragmentos/litro. Junto con ello, es significativo el hecho de que en tres casos en que se ha podido identificar varios fragmentos de una misma pieza, todos ellos provienen también de la Unidad 19. Más aún, casi todos los fragmentos de cada una de las tres piezas señaladas provienen de un espacio no mayor de $4 \mathrm{~m}^{2}$. Estos datos indican que el centro del basural de tiempo inka se concentra en la parte suroeste del Patio Sur, en un espacio que en total no debió ser superior a los $70 \mathrm{~m}^{2}$, y que, pese a las grandes intervenciones posteriores del terreno, las basuras se mantuvieron cerca del lugar donde fueron depositadas originalmente. Por cierto, si bien la densidad de fragmentos diagnósticos en el espacio al norte y al este del área del nuclear del basural es menor, sigue siendo alta al compararla con los valores que hemos estimado para otros sitios inkas de Chile central (tabla 2). Esto significa que dicha área también formaría parte del basural, aunque al anillo exterior de la concentración.
Asimismo, es necesario poner las evidencias encontradas bajo los patios del Palacio de la Real Aduana en el contexto de otros hallazgos hechos en las inmediaciones, también en el marco de rescates arqueológicos asociados a obras realizadas en el subsuelo de edificaciones cercanas (fig. 1): los estacionamientos subterráneos del ex Hotel City (Galarce et al. 2014) y la remodelación de la Cripta de la Catedral de Santiago (Rivas 2008). En ambos casos, si bien no se pudo identificar con claridad un estrato inka debido a las abundantes remociones coloniales e históricas, sí se recolectaron fragmentos diagnósticos de tiempos inkas que muestran características similares a los aquí estudiados. Aunque en menor densidad que el área excavada en el Palacio de la Real Aduana, aquellos fragmentos resultan mucho más densos que los de otros sitios inkas de Chile central (tabla 2). De esta manera, pese a que existe discontinuidad espacial entre estos tres sitios (Palacio de la Real Aduana, ex Hotel City y Cripta de la Catedral), ya que en los puntos intermedios no se han realizado excavaciones arqueológicas, creemos factible suponer que se trataría de la misma ocupación arqueológica, que contaría con al menos unos $150 \mathrm{~m}$ de largo en su rumbo norte-sur. 
En otras intervenciones arqueológicas de rescate realizadas hacia el este y el oeste del área que aquí hemos detallado, asociadas a la construcción de estaciones del Metro (fig. 1), la situación parece ser muy distinta. Si bien la información existente de dichos estudios no está sistematizada como para realizar cálculos de densidad, pareciera que en ellas la presencia de basuras de tiempos inkas es mucho menos significativa (C. Prado 2016, comunicación personal). Estaríamos entonces frente a un área de depósitos de basuras secundarias que formaría parte de un sitio mayor en el cual debiera existir por lo menos otro sector en donde se realizó un uso intensivo de pucos, chua, jarros, aysana y maka y donde deberían haberse ubicado las estructuras de combustión que dieron origen a los carbones que caracterizan el estrato inka en el segmento excavado. Lamentablemente aquellos rasgos arqueológicos no han sido detectados, aunque presumimos que se encuentran en las inmediaciones del basural.

\section{FUNCIONALIDAD DEL ASENTAMIENTO}

La inusual cantidad de basuras de tiempos inkas y sus características nos proponen una interpretación de la funcionalidad del sitio estudiado y del rol que cumplió en el despliegue del Tawantinsuyu en su territorio más austral.

En primer lugar, en ningún otro sitio de tiempos inkas conocido en Chile central se utilizó y luego descartó una cantidad tan alta de vasijas con iconografía en sus superficies, es decir, portadoras de una singular agencia simbólica. Una parte importante de estas vasijas corresponden a maka, chua y aysana (fig. 11), las cuales han sido definidas por Bray (2003:5) como equipamiento de una cocina de élite inka. Sin embargo, su uso extendido en lugares periféricos a la élite cuzqueña y lo usual que resultan en tumbas de muchas personas, incluso en lugares muy alejados del Cuzco como el actual centro de Chile (p.e., Quevedo et al. 1999, Cantarutti \& Mera 2002, Baudet 2008, Correa et al. 2008, Fuenzalida 2015), son datos que no apoyan dicha definición. De hecho, pensamos que su redundancia a lo largo de toda la extensión territorial y social del Tawantinsuyu se debe a ser componentes esenciales de la liturgia ceremonial del Estado. Más aún, al revisar cómo se expresan estas vasijas en distintas regiones, es evidente que su poder litúrgico está en la forma de los objetos, no en el origen de la manufacturación, mayormente local, ni en la iconografía que sobre ellos se despliega, también local (Cornejo 2001a). El conjunto, tal como señalan Páez y Giovannetti (2008), representa el valor sincrético de estos objetos al integrar lo local como parte de su agencia simbólica, aunque según determinadas restricciones.

Junto con estas vasijas litúrgicas, hay un conjunto importante de vasijas locales de tiempos inkas, en especial pucos y jarros, que exhiben sobre todo iconografía de origen diaguita que, como ya dijimos, llegan a Chile central asociadas a la expansión cuzqueña, junto con algunos pocos motivos de origen inka. No existe una buena hipótesis para caracterizar el rol de estos objetos locales más allá del evidente uso como servicio para comer y beber, pero su presencia común en los ajuares funerarios de la época, que suelen incluir además vasijas litúrgicas inkas (Quevedo et al. 1999, Cantarutti \& Mera 2002, Baudet 2008, Correa et al. 2008, Fuenzalida 2015), nos permite suponer que también fueron conceptualizadas como componentes esenciales del ceremonial local.

Esta gran concentración de vasijas para comer y beber, revestidas de la agencia simbólica de sus formas y sus iconografías, parece remitir a los festines o banquetes políticos que se han descrito como parte esencial de la política colonial inka (Murra 1980; Bray 2003, 2004; Dillehay 2003), donde abundante comida y chicha jugaron un papel central en la política de reciprocidad de las autoridades estatales hacia las poblaciones locales. Uno de los ejemplos arqueológicos de estos eventos mejor descrito es la acumulación de restos de platos y jarros de estilos inkas encontrados junto a la plaza principal de Huánuco Pampa (Morris 1982, Morris \& Thompson 1985).

Este ejemplo podría indicar que la concentración de basuras inkas encontrada bajo el centro histórico de Santiago se hallaría también en el entorno de una plaza o kancha donde habrían ocurrido los banquetes que generaron estas basuras. Este espacio, tal como han propuesto Stehberg y Sotomayor (2012), podría coincidir con la Plaza de Armas en torno a la cual Pedro de Valdivia fundó la ciudad de Santiago, pues se podría suponer que una kancha, es decir, un lugar despejado y plano, era idóneo para que el alarife Gamboa comenzara a trazar la futura urbe. Por desgracia, aún no hay evidencias de un centro urbano inka como el que estos autores proponen (Stehberg \& Sotomayor 2012: 133); de existir, fueron obliteradas por las construcciones coloniales e históricas que en el lugar se han sucedido. 


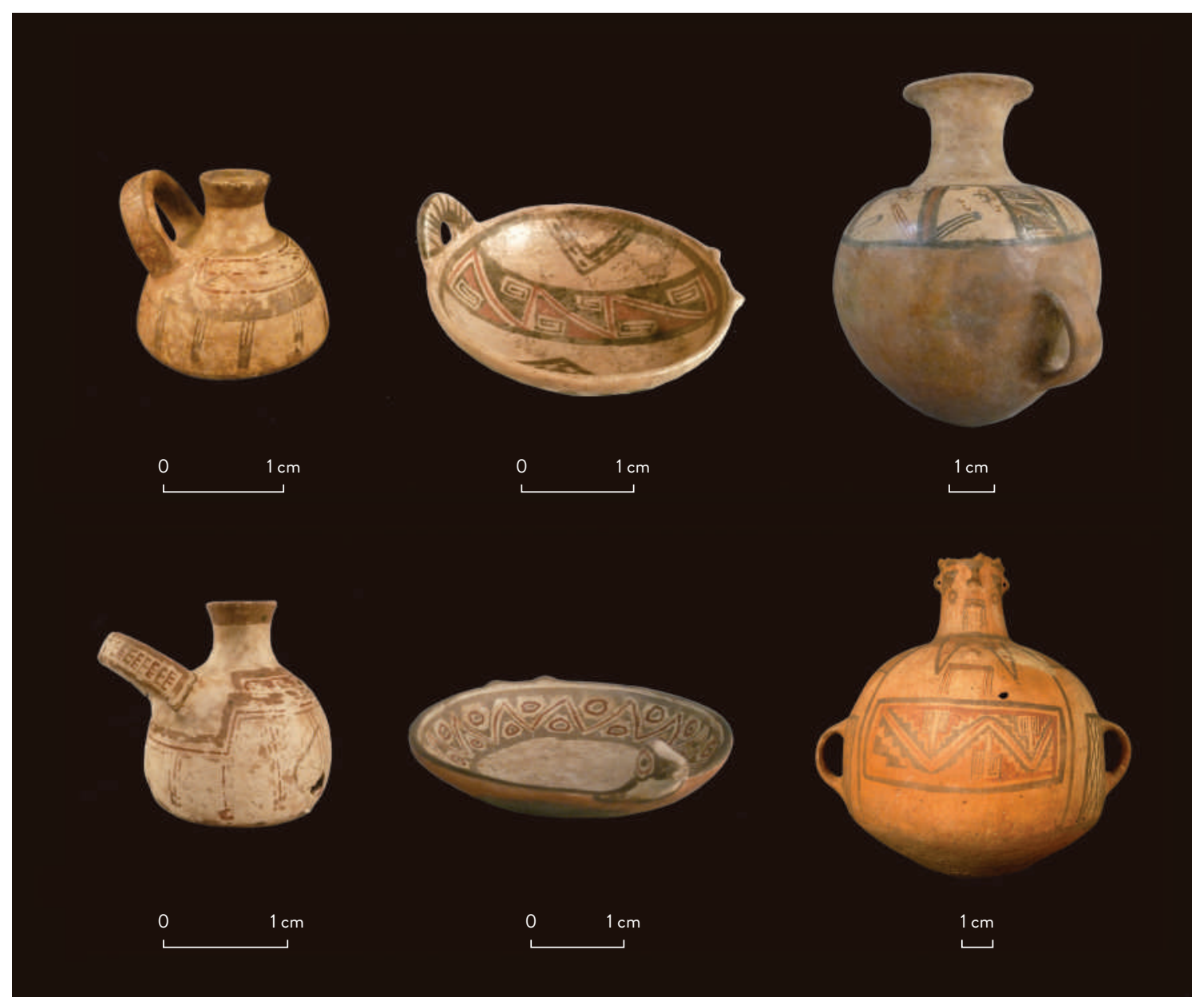

Figura 11. Ejemplos de las vasijas litúrgicas inkas de Chile central (Colección del Museo Chileno de Arte Precolombino: MAs-2966, MAS-890, MAS-853, MAS-2694, MAS-2964 y мСHAP 0351). Figure 11. Examples of liturgical Inka vessels of Central Chile (Museo Chileno de Arte Precolombino Collection: MAS-2966, MAS-890, MAS-853, MAS-2694, MAS-2964 y MCHAP 0351).

En todo caso, la información proporcionada por el cronista Rosales (1877 [1674]) es contradictoria con esta idea. Rosales señala que, en el momento de su arribo al valle del río Mapocho, Pedro de Valdivia intentó fundar la ciudad de Santiago en la margen norte del río Mapocho, a unos centenares de metros de su ubicación definitiva. Sin embargo, en el momento de hacerlo se le acercó un jefe local llamado Loncomilla quien le recomendó "que otro mexor sitio avia de la otra randa del rio, a la parte del sur, donde los Ingas avian hecho una poblacion, que es el lugar donde oy está la ciudad de Santiago" (Rosales 1877 [1674]: 383). Esto quiere decir que el asentamiento inka bajo la actual ciudad de Santiago pasó desapercibido para Valdivia y su gente, y que, de ser así, seguramente no era de una magnitud significativa. De ser correcta esta información (que debe ponderarse, ya que es posterior a la llegada de Valdivia al Mapocho), contradice también uno de los argumentos centrales de Stehberg y Sotomayor (2012: 133) para señalar que en este lugar existiría un centro urbano inka. Según ellos, Pedro de Valdivia habría sabido de su existencia antes de comenzar su viaje. Para ello, los autores interpretan un discurso de Pedro de Valdivia en Copiapó que el cronista Gerónimo de Bibar registró de oídas. En él, Valdivia habría señalado que venía a poblar "un pueblo como en cuzco" ubicado en el río Mapocho (Stehberg \& Sotomayor 2012: 102). Sin embargo, en un principio no habría intentado ocupar dicho "poblado", algo poco común en un conquistador español que, además, traía aquello como su misión. Por lo demás, en 
su referencia directa al viaje de Valdivia hacia el valle del Mapocho, el mismo Bibar señala que este "pensaba fundar un pueblo [sic]" (Bibar 1966 [1558]: 34). Con todo, la referencia al tambo junto a la plaza en el Acta del Santiago de 1541 (1861) y un plano anónimo de la fundación de la ciudad de Santiago de cerca del 1900, que incluye una alusión a "Paredones o Tambillo del Inca", apoyan la idea de que en el entorno del lugar donde los españoles fundaron la ciudad de Santiago existió algún tipo de construcción inka.

Aun así, es evidente que este asentamiento se configuró como un lugar central en las complejas relaciones entre los representantes del Tawantinsuyu y de las comunidades locales, por lo cual debió incluir alguna infraestructura necesaria para sus funciones. Es muy probable que incluyera edificaciones como kallanka y kolaka, además de espacios abiertos como kancha y un ushnu. Por otra parte, su escala constructiva sería similar a la de otros sitios con arquitectura inka en Chile central y en ningún caso mayor que la de otros sitios en el sur del Kollasuyu que por tener un ushnu podrían ser de relevancia regional, tal como Viña del Cerro en Copiapó (Niemeyer et al. 1984) o el Shincal de Quimivil (Raffino et al. 2015). Se debe considerar, no obstante, que en ninguna de las excavaciones realizadas en el área hay evidencias de basuras distintas a la alfarería (complejos de morteros, tumis, conchas de moluscos, restos de camélidos, etc.) como las descritas para el espacio cercano al ushnu del Shincal de Quimivil (Corso et al. 2015: 99).

Este tipo de asentamientos principales inkas, ubicados en lugares estratégicos a lo largo de los territorios donde este Estado se expandió, han sido llamados centros administrativos (Raffino 1981, Williams 2000, Sánchez 2004). Nosotros preferimos referirnos al lugar como un centro político, ya que, como se verá a continuación, el contexto arqueológico que hemos estudiado parece relacionarse principalmente con la esfera política. En todo caso, es evidente que lo administrativo y lo político suelen estar muy interrelacionados.

Sobre el tenor preciso de los eventos que aquí ocurrieron es muy difícil tener algún grado de detalle, pues el registro etnohistórico sobre el tema, comparado con el de otras regiones (p.e., Capriles \& Revilla 2006), es muy poco detallado. A pesar de todo, creemos que las características estructurales de las vasijas utilizadas para comer y beber nos pueden dar algunas luces sobre determinados aspectos, en virtud de los roles litúrgico y sincrético que fueron impresos en ellas.

\section{ALFARERÍA Y POLÍTICA}

Se debe partir señalando que la inmensa mayoría de las vasijas litúrgicas descartadas (Tipos 4, 5, 6, 9 y las aysana del Tipo 8) no presentan características tecnológicas, especialmente pastas y cocción, que hagan suponer un origen en el Cuzco o en otro lugar cercano al núcleo inka. Ello significa que en estos ceremoniales se utilizaron versiones locales de las vasijas litúrgicas inkas, las que de hecho son algo distintas. La forma de las maka de la región -uno de los componentes centrales de estas instancias- difiere del estándar cuzqueño: su base es plana y no apuntada, como en el resto del Tawantinsuyu, y tampoco exhiben la característica asa de suspensión superior (Sanhueza 2001).

Junto con lo anterior, los patrones iconográficos de las maka, chua y aysana del sitio (y en general del contexto alfarero inka de la región) son también distintos al resto del Tawantinsuyu. En los territorios conquistados por los cuzqueños, estas vasijas litúrgicas se caracterizan por mantener en términos generales los patrones morfológicos inkas, lo que permite reconocerlas como tales, mientras que en su superficie incorporan también abundantes elementos propios de las tradiciones locales, lo que podría corresponder a la representación de los acuerdos políticos establecidos entre lo local y lo inka. Uno de los ejemplos paradigmáticos de esta simbología ecuménica entre lo inka y lo local ocurre en la región atacameña. Allí, las vasijas de la tradición alfarera local San Pedro, de tiempos preinkas, no presentaban iconografía. En consecuencia, las vasijas litúrgicas inkas manufacturadas localmente tampoco pintan motivos, sino que solo son coloreadas en rojo o negro, alejándose bastante de los parámetros simbólicos cuzqueños (Cornejo 2001a).

En Chile central, sin embargo, incluyendo las vasijas consumidas en el sitio estudiado, las alfarerías no ostentan de manera absoluta patrones iconográficos de las poblaciones locales Aconcagua, ${ }^{7}$ sino que, junto con algunos patrones inkas, dominan los de la tradición diaguita, población originaria de los territorios semiáridos ubicados algunos centenares de kilómetros al norte de valle del Mapocho. Diferentes autores (Silva 1985, Cornejo 2001b, Sánchez 2004) han propuesto que esta singular situación se debe al importante rol que jugaron los diaguitas en la anexión de Chile central al Estado cuzqueño, pero dicha explicación no es suficiente para entender por qué se excluye de este campo simbólico a la iconografía local. 
PATRÓN ZIG-ZAG

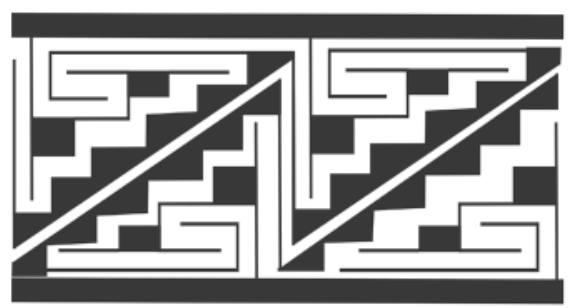

Familia elementos opuestos pareados
PATRÓN ONDAS

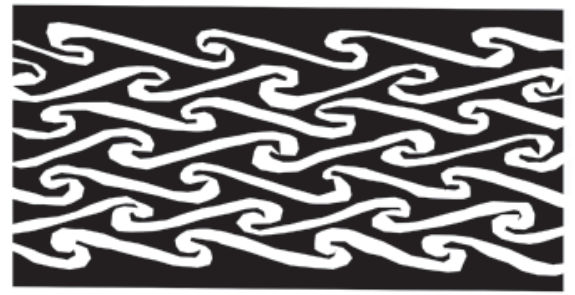

Familia sin elementos opuestos pareados

Figura 12. Ejemplos de las familias de motivos característicos del diaguita preinka. Figure 12. Examples of the families of characteristic Pre-Inka Diaguita motives.

Lo anterior no quiere decir que lo local se ausente del todo en este contexto, sino que para manifestarse debió seguir algunos principios impuestos que responden relativamente a la misma lógica de las vasijas litúrgicas inkas, lógica que contrapone las formas de las piezas con la iconografía. Por un lado, para la función de servir comida están los pucos cuya forma era común en la tradición local aconcagua desde el año 1000 DC aprox., (Sánchez \& Massone 1995), pero que ya no despliegan su iconografía tradicional Aconcagua, sino que portan motivos diaguita por lo general constreñidos dentro de bandas en el interior de la pieza, ya sea con una base de pintura blanca, engobe rojo o engobe del color de la pasta. Una parte importante de estos, aquellos con pintura blanca de base para la iconografía, son también muy comunes en los contextos funerarios (Tipos 7, 7a y 7b), si bien los que hemos clasificado como Tipo 1 son escasísimos en los ajuares (p.e., la pieza EDQ1034 del Estadio de Quillota, Fuenzalida 2015 Anexos: 114).

Por otro lado, para la función de beber se utilizaron jarras del tipo local Viluco, con iconografía diaguita sobre una base de pintura blanca (Tipo 8) y otras cuya forma precisa no es clara. Estas últimas podrían ser parte de la tradición de jarras aconcagua preinkas, las que también muestran iconografía diaguita pero pintada sobre un engobe rojo anaranjado o del color de la pasta (Tipo 3). Las primeras son muy usuales en los contextos funerarios (Latcham 1928, Mostny 1947, Correa et al. 2008, Fuenzalida 2015), al contrario de aquellas que no presentan una base de pintura blanca (p.e., Stehberg \& Sotomayor 2012: fig. 2).
Si bien somos conscientes de que no es posible hacer una lectura directa de quienes actuaron en este centro político inka a partir de las características de la cultura material -cosa advertida hace bastante por Hodder (1982)-, sí creemos posible entrever algunos principios estructurantes del campo social y político que en él se desplegó considerando los rasgos estructurales de las vasijas descartadas.

En primer lugar, las vasijas litúrgicas inkas encontradas en el sitio, al igual que en el resto de Chile central, no fueron confeccionadas mayoritariamente siguiendo los cánones inkas aplicados en otras regiones, sobre todo al dejar fuera a la iconografía local Aconcagua. Una posible interpretación de esto podría encontrarse en el contexto de vasijas de tiempos inkas en el propio territorio diaguita, donde también ocurre una situación de exclusión de elementos iconográficos preinkas.

El repertorio de motivos diaguitas clásicos incluye una serie de patrones construidos con principios de simetría (Cornejo 1989, González 2013) que se pueden dividir en dos grandes familias (fig. 12): (a) una que opone elementos pareados que han sido trasladados y rotados, tales como los conocidos patrones zigzag, doble zigzag y cadenas (Cornejo 1989: 66) y (b) otra en que los principios de simetría no forman oposiciones pareadas, especialmente el patrón ondas (Cornejo 1989: 67). Las proporciones de esta última familia en tiempos preinkas (Fase I y II), al menos en los platos zoomorfos, se mantiene en el rango 25-30\%, mientras que en tiempos inkas (Fase III) disminuye a menos del $10 \%$; en cambio, los patrones zigzag y doble zigzag 
que generan oposiciones pareadas aumentan de modo significativa (Cornejo 1989: cuadro 13). Además, si consideramos únicamente las vasijas litúrgicas inkas de dicha región (González 2013), además de algunos patrones cuzqueños, los motivos de la tradición diaguita preinka que presentan solo corresponden a (a), con la excepción de una versión bícroma (negro sobre blanco) muy estilizada del patrón ondas (Cornejo 1989: 67, González 2013: 265).

Este esfuerzo simbólico por denotar la oposición entre los diaguitas de tiempos inkas ha sido estudiado por González (1998), quien a partir de algunos casos icónicos ha indicado la adherencia a principios ideológicos propiamente inkas pero que se sustentarían en su tradición preinka. Por otro lado, en su estudio de la semiótica preinka e inka en el valle del Aconcagua, Troncoso (2005: 33) destaca las grandes diferencias que existen entre lo local y lo inka, y enfatiza que el sistema de representación inka busca la "aplicación de un sistema semiótico muy similar para las distintas expresiones artísticas de este tiempo, tanto en la zona como a lo largo del Tawantinsuyu". Así, se subraya un esfuerzo por definir con precisión el campo de representación.

De hecho, se hallan solo motivos de la familia iconográfica diaguita (a) en las vasijas litúrgicas de Chile central, sobre todo los patrones zigzag y doble zigzag (Cornejo 1989: 66). Podríamos pensar que esta opción habría marginado del campo simbólico a los patrones locales Aconcagua, la mayor parte de los cuales no sigue dicha regla de construcción. Aunque se ha sostenido que sí existían principios de organización dual en la sociedad Aconcagua (Sánchez \& Massone 1995, Falabella et al. 2016), estos se referirían a criterios básicos de oposiciones presentes en casi cualquier sociedad (centro-periferia, hombre-mujer, exterior-interior, entre otros), y no estarían representados por medio de una semiótica explícita de oposición de pares rotados. Los motivos Aconcagua, tales como trinacrios, líneas onduladas o pestañas (fig. 13), se basan principalmente en la traslación de un elemento, formando una figura de componentes iguales y no opuestos. Al rotar en torno al centro del cuerpo de las piezas, estos motivos -especialmente en el caso de los pucos- forman cuatriparticiones o triparticiones, pero dichas formaciones siguen siendo de elementos idénticos y no contrapuestos.

Proponer una interpretación de la ideología representada en la estructura básica de la iconografía Aconcagua carece de base, pero es evidente que no refiere

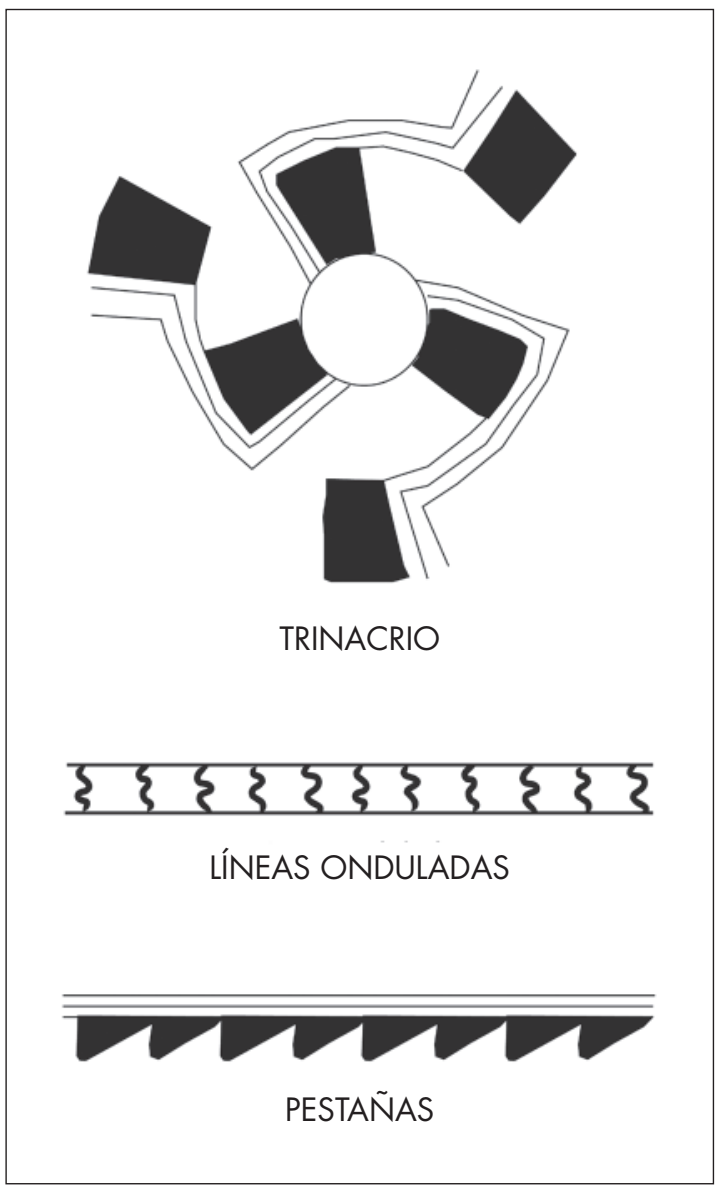

Figura 13. Ejemplos de motivos comunes de la iconografía aconcagua preinka (adaptado de Sánchez \& Masone 1995: fig. 20). Figure 13. Examples of common motives of the pre-Inka aconcagua iconography (adapted from Sánchez \& Masone 1995: fig. 20).

a principios de dualidad similares a los de la cultura Diaguita o Inka. Este hecho marca una importante diferencia con otro tipo de contexto de tiempos inkas, los ajuares funerarios, donde también se consumen una gran cantidad de vasijas y es común que se mezclen las vasijas litúrgicas inkas con pucos y jarros que exhiben motivos propios de la tradición local Aconcagua (p.e., Quevedo et al. 1999, Cantarutti \& Mera 2002, Baudet 2008, Correa et al. 2008, Fuenzalida 2015).

La esfera local, por su parte, está presente en el basural estudiado en la medida en que cumple con las mismas restricciones iconográficas que las vasijas litúrgicas, al dejar de lado la iconografía local pero rescatar una de sus formas emblemáticas -los pucos- e incorporar a la vez formas que no existían con anterioridad. Algunas 
de estas vasijas, sobre todo los tipos 1 y 3 , se destinan principalmente a los acontecimientos de este centro y se segregan de los contextos funerarios. De esta manera, pareciera que lo local establece una clara dicotomía entre el ceremonial público (el centro político), que sigue las reglas impuestas por la ocupación inka, y el ceremonial privado (lo funerario), donde se incorporan elementos inkas pero se continúa acogiendo los principios iconográficos de la tradición local. En el contexto público existiría entonces una suerte de represión de elementos locales.

\section{CONCLUSIONES}

La base del ceremonial que tuvo lugar en el centro político del río Mapocho era parte del extendido sistema de "reciprocidad" inka en el que festines de comida y bebida generaban el campo adecuado para asegurar la dominación sobre las poblaciones locales. En estos ceremoniales, las vasijas litúrgicas inkas y las propias de la tradición local, pero revestidas de la iconografía oficial, jugaban un papel central en el escenario simbólico que para estos efectos se construía. Esto ocurría bajo una interpretación particular y distinta a la de otros territorios del Kollasuyu, ya que los elementos iconográficos de la población local Aconcagua fueron remplazados por patrones diaguitas. Los conceptos locales Aconcagua, por su parte, estaban presentes en las formas de sus vasijas tradicionales o en el desarrollo de nuevas categorías de vasijas para estos ceremoniales, pero en ambos casos asumiendo los parámetros iconográficos establecidos por la dominación extranjera.

En virtud de lo anterior, en el contexto señalado se produce un interesante enfrentamiento entre la reiteración de una iconografía impuesta que alude a la oposición de partes iguales, principios que harían referencia a la dualidad, complementariedad y reciprocidad, y la negación de los principios iconográficos locales ajenos a esas ideas. Apropiándonos de un viejo concepto acuñado por Marx, diríamos que se produce entonces una especie de fetichismo de la oposición dual, según el cual el poder del símbolo de dos iguales contrapuestos y complementarios esconde las asimetrías existentes entre el poder extranjero y la población local que sufre la represión de un componente importante de su tradición. Es probable que esta asimetría fuera el centro de las negociaciones políticas ocurridas junto al río
Mapocho, donde el fetiche de la dualidad seguramente aportaba en la construcción de un segundo fetiche, el de la reciprocidad, donde abundante comida y bebida son intercambiadas por la aceptación del dominio, el trabajo al servicio del poder extranjero y la pérdida de la autonomía.

Las poblaciones locales hicieron una diferencia importante entre este campo político y su vida privada, ya que incorporaron en estos festines algunas vasijas de tipos que no existían previamente y que son marginados casi por completo de la esfera más privada, como los utensilios domésticos y los ajuares funerarios, donde por lo demás siguen siendo frecuentes los pucos y jarros portadores de la iconografía tradicional Aconcagua. Pareciera que, al menos en parte, los fetiches de la dualidad y la reciprocidad fueron reconocidos como tales por los Aconcaguas y marcaron, como señala Fuenzalida (2015: 100), un juego entre la resistencia y el consentimiento.

Los datos que hemos presentado señalan con claridad que el juego político desarrollado en el centro político del Mapocho obedeció en gran medida a premisas ideológicas de la cultura Diaguita, que sintonizaban con concepciones del mundo inka. $\mathrm{Al}$ respecto, se ha planteado con anterioridad que los diaguitas tuvieron un papel importante en la expansión del Tawantinsuyu en el sur del Kollasuyu (Silva 1985; Cornejo 2001b; entre otros), lo que según Sánchez (2004) fue producto de la interacción ya existente entre aconcagua preinka y diaguita preinka, sobre todo en la cuenca superior del río Aconcagua.

La conclusión de Malpass y Alconini (2010) sobre la flexibilidad del modelo de dominio inka para recurrir al control local tendría un muy buen ejemplo en el confín del Kollasuyu. Este amplio y lejano territorio habría sido incorporado al Estado Inka por medio del potenciamiento político de un grupo particular -los diaguitas- con el cual existían ciertas afinidades ideológicas y que se habría convertido en representante de lo inka. Esto sin duda explicaría la preeminencia ideológica de la iconografía diaguita como medio de lo que hemos llamado el fetiche de la dualidad representado en los objetos utilizados en el centro diaguita-inka junto al río Mapocho, así como en una amplia porción del extremo austral del Tawantinsuyu (Cornejo 2001b). 


\section{NOTAS}

${ }^{1}$ Todas las fechas $\mathrm{C}^{14}$ que se ofrecen han sido calibradas con el Software Calib 7.0.4, con la curva de calibración SHCal13 y se presentan a la probabilidad del $94 \%$.

${ }^{2}$ El Palacio de la Real Aduana, así como el sitio arqueológico bajo los patios, son monumentos nacionales de acuerdo a la Ley de Monumentos Nacionales $\left(n^{\circ} 17.288\right)$ y la intervención en ellos esta normada por el Consejo de Monumentos Nacionales.

${ }^{3}$ Unidad $19 \mathrm{~N}(2 \mathrm{~b}, 2 \mathrm{c}$ y $3 \mathrm{a})=0,30 \mathrm{~m}^{2}$, Unidad 20 (estratos $3 \mathrm{a}, 3 \mathrm{~b}$ y $4 \mathrm{a})=0,90 \mathrm{~m}^{2}$, Unidad 21 (estratos $5 \mathrm{a}, 5 \mathrm{~b}$ y $\left.6 \mathrm{a}\right)=1,69$ $\mathrm{m}^{2}$ y Unidad 22 (Estratos 2c, 2b, 3a y Rasgo 8) $=0,91 \mathrm{~m}^{2}$.

${ }^{4}$ Para realizar este promedio se utilizó el algoritmo contenido en el Software Calib 7.0.4.

${ }^{5}$ El 0,01 de probabilidad se encuentra en el rango de 1604 a 1608 años DC y no lo hemos considerado dada su baja probabilidad.

${ }^{6}$ El cálculo de la densidad en los sectores desde donde no fue posible asilar un estrato de ocupación inka, se estimó a partir de las unidades donde esto sí fue posible, un espesor mínimo de $10 \mathrm{~cm}$.

${ }^{7}$ En todo el sitio se rescataron solo 13 fragmentos de vasijas del tipo Aconcagua Negro Sobre Salmón, lo que representaría el 2,9\% de vasijas con motivos pintados prehispánicos en el sitio.

Reconocimientos Este trabajo es resultado del proyecto "Chile antes de Chile": Museo Chileno de Arte Precolombino-Minera Escondida. Compromete nuestra gratitud el equipo de arqueólogos y conservadores que participaron en las extensas jornadas de excavación y en los estudios de los diferentes materiales arqueológicos. Agradecemos también la ayuda de Lorena Sanhueza R. en la revisión de nuestra clasificación cerámica y por sus comentarios al manuscrito.

\section{REFERENCIAS}

Actas del Cabildo de Santiago. 1861. Primer Libro de Actas del Cabildo de Santiago llamado jeneralmente libro becerro de 1541-1557. Colección de Historiadores de Chile y documentos relativos a la Historia de Chile. Imprenta del Ferrocarril. Santiago.

Ampuero, G. 1978. Cultura diaguita. Santiago: Ministerio de Educación, Serie Patrimonio Cultural Chileno.

Baudet, D. 2008 Ms. Análisis cerámico sitio Las Tinajas.

BAUdeT, D. \& J. BAEZA. 2013 Ms. Informe análisis cerámico alfarería baja y alta temperatura sitio MCHAP. Informe Proyecto Chile Antes de Chile, Museo Chileno de Arte Precolombino-Minera Escondida.

BIBAR, G. 1966 [1558]. Crónica y relación copiosa y verdadera de los Reynos de Chile. Santiago: Fondo Histórico y Bibliográfico José Toribio Medina.
Botтo, C. 1989. Palacio de la Real Aduana. Un metro de cinco siglos. Tesis para optar al grado de Licenciatura en Antropología con mención en Arqueología y Prehistoria. Departamento de Antropología, Facultad de Ciencias Humanas, Universidad de Chile. Santiago.

BRAY, T. 2003. Inca pottery as culinary equipment: food, feasting, and gender in imperial state design. Latin American Antiquity 14: 1-22. Cambridge.

BRAY, T. 2004. La alfarería imperial inka: una comparación entre la cerámica estatal del área de Cuzco y la cerámica de las provincias. Chungara 36 (2): 365-374. Arica.

Calderari, M. \& V. Williams. 1991. Re-evaluación de los estilos cerámicos incaicos en el Noroeste Argentino. Comechingonia 9: 75-95. Córdoba.

Cantarutti, G. \& R. Mera. 2002. Alfarería del cementerio estación Matucana: ensayo de clasificación y relaciones con la cerámica del Período Inca de Chile central y áreas vecinas. Werkén 3: 147-170. Santiago.

Cantarutti G. \& R. Mera. 2004. Estadio fiscal de Ovalle: redescubrimiento de un sitio diaguita-inca en el valle del Limarí. Chungara 36: 833-845. Arica.

CAPRILES, J. \& C. Revilla. 2006. Ocupación inka en la región kallawaya: oralidad, etnohistoria y arqueología de Camata, Bolivia. Chungara 38 (2): 223-238. Arica.

Contreras, C. 2013 Ms. Informe de análisis lítico: sitio Museo Chileno de Arte Precolombino. Informe del rescate arqueológico. Informe Proyecto Chile Antes de Chile, Museo Chileno de Arte Precolombino-Minera Escondida.

CoRnejo, L. 1989. El plato zoomorfo diaguita: variabilidad y especificidad. Boletín del Museo Chileno de Arte Precolombino 3: 47-80. Santiago.

Cornejo, L. 2000. Clasificación de vasijas de cerámica: un estudio comparativo. En Actas del XIV Congreso Chileno de Arqueología, Tomo I, pp. 205-224. Copiapó: Sociedad Chilena de Antropología-Museo Regional de Copiapó.

Cornejo, L. 2001a. Alfarería y política. En Tras la huella del Inka en Chile, C. Aldunate \& L. Cornejo, Eds., pp. 114-121. Santiago: Museo Chileno de Arte Precolombino.

Cornejo, L. 2001b. Los Inka y sus aliados diaguita en el extremo austral del Tawantinsuyu. En Tras la huella del Inka en Chile. C. Aldunate \& L. Cornejo, Eds., pp. 74-89. Santiago: Museo Chileno de Arte Precolombino.

Cornejo, L. 2003. Las escudillas Diaguita: Formas y diseño. En Actas del Cuarto Congreso Chileno de Antropología, pp. 1344-1350. Santiago: Colegio de AntropólogosDepartamento de Antropología, Universidad de Chile.

Cornejo, L. 2014. Sobre la cronología del inicio de la imposición cuzqueña en Chile. Estudios Atacameños 47: 101-116. San Pedro de Atacama.

Cornely, F. 1956. Cultura diaguita chilena: y cultura de El Molle. Santiago: Editorial del Pacífico.

Cornely, F. 1962. El Arte decorativo preincaico de los indios de Coquimbo y Atacama. Diaguitas chilenos. La Serena: Ilustre Municipalidad de La Serena. 
Correa, I., F. Bahamondes, M. Uribe \& C. Solervicens. 2008. Contextos alfareros de interacción social: lo local y lo foráneo en el cementerio inca de Quinta Normal. Revista Chilena de Antropología 19: 143-171. Santiago.

Corso, M., J. Gianelli \& M. OCHOA. 2015. Caracterización cerámica de dos momentos de ocupación en el ushnu de El Shincal de Quimivil. En Una capital inka al sur del kollasuyu: el Shincal de Quimivil, R. Raffino, L. Iácona, R. Moralejo, D. Gobbo \& M. Couso, Eds., pp. 85-104. Buenos Aires: Fundación de Historia Natural Félix de Azara Departamento de Ciencias Naturales y Antropológicas. CEBBAD-Instituto Superior de Investigaciones-Universidad Maimónides.

Dillehay, T. 2003. El colonialismo inka, el consumo de chicha y los festines desde una perspectiva de banquetes políticos. Boletín de Arqueología PUCP 7: 355-363. Lima.

Falabella, F., D. Pavlovic, M. T. Planella \& L. Sanhueza. 2016. Diversidad y heterogeneidad cultural y social en Chile Central durante los Períodos Alfareros Temprano e Intermedio Tardío (300 años AC, a 1450 años DC). En Prehistoria en Chile. Desde sus primeros habitantes hasta los Incas, Falabella, F., M. Uribe, L. Sanhueza, C. Aldunate \& J. Hidalgo, Eds., pp. 365-400. Santiago: Editorial Universitaria.

Fernández BacA, J. 1971. Motivos de ornamentación de la cerámica inca del Cuzco. Lima: Librería Stadium.

Fuenzalida, N. 2015. La vida en la muerte: resistencia e incanización en la alfarería fúnebre de las comunidades del curso medio-inferior del Aconcagua. Memoria para optar al título de Arqueóloga. Departamento de Antropología, Facultad de Ciencias Sociales, Universidad de Chile. Santiago.

Galarce, P., G. Santander \& C. Rodillo. 2014 Ms. Informe final excavación arqueológica sitio Ex Hotel City. Arqueos Chile Consultores en Arqueología Ltda.

González, C. 2000. Comentarios arqueológicos sobre la problemática inca en Chile Central (primera parte). Boletín de la Sociedad Chilena de Arqueología 29: 39-50. Santiago.

GonzÁlez, O. 1998. Doble reflexión especular en los diseños diaguita inca: de la imagen al símbolo. Boletín del Museo Chileno de Arte Precolombino 7: 38-52. Santiago.

GonzÁlez, P. 2001. El arte visual diaguita preincaico y su vinculación con tradiciones chamánicas sudamericanas. En Actas del XIII Congreso Nacional de Arqueología Argentina, Tomo I, pp. 223-233. Córdoba: Brujas.

GonzÁlez, P. 2013. Arte y cultura diaguita chilena. Simetría, simbolismo e identidad. Serie Monográfica No 2. Santiago: Sociedad Chilena de Arqueología.

Hodder, I. 1982. Symbols in action: ethnoarchaeological studies of material culture. Cambridge: Cambridge University Press.

Lagiglia, H. 1978. La Cultura de Viluco del centro oeste argentino. Revista del Museo de Historia Natural III (1-4): 227-265. San Rafael.

LAтснам, R. 1928. La alfarería indígena chilena. Santiago: Sociedad Impresora y Litográfica Universo.
LATORRe, V. 2013 Ms. Informe de análisis material metálico sitio Museo Chileno de Arte Precolombino (Región Metropolitana, Chile). Informe Proyecto Chile Antes de Chile, Museo Chileno de Arte Precolombino-Minera Escondida.

LóPEZ, P. 2013 Ms. Análisis zooarqueológico y tafonómico del sitio MCHAP (Región Metropolitana, Chile). Segunda etapa. Informe Proyecto Chile Antes de Chile, Museo Chileno de Arte Precolombino-Minera Escondida.

Malpass, M. \& S. Alconini. 2010. Provincial Inka studies in the twenty-first century. En Distant provinces in the Inka Empire: toward a deeper understanding of Inka imperialism, M. Malpass \& S. Alconini, Eds., pp. 1-13. Iowa: University of Iowa Press.

Morris, C. 1982. The infrastructure of inka control in the peruvian central highlands. En The Inca and Aztec states, 1400-1800: anthropology and history, G. Collieret, R. Rosaldo \& J. Wirth, Eds., pp. 153-171. New York: Academic Press.

Morris, C. \& D. Thompson. 1985. Huánuco Pampa. Londres: Thames and Hudson.

Mostny, G. 1947. Un cementerio incásico en Chile central. Boletín del Museo Nacional de Historia Natural xxin: 17-41. Santiago.

Murra, J., 1980. Economic organization of the Inka state. Connecticut: JAI Press.

Niemeyer, H., M. Cervellino \& E. Muñoz. 1984 Viña del Cerro: metalurgia inka en Copiapó, Chile. Gaceta Arqueológica Andina 9: 6-7. Lima.

Páez, M. \& M. Giovannetti. 2008. Intersecciones y síntesis: sincretismos en los platos del Período Inkaico en el Noroeste Argentino. Arqueología Suramericana 4 (2): 169-190. San Fernando del Valle de Catamarca.

Pavlovic, D., A. Troncoso, R. Sánchez \& D. Pascual. 2012. Un tigre en el valle. Vialidad, arquitectura y ritualidad incaica en la cuenca superior del río Aconcagua. Chungara 44 (4): 551-569. Arica.

Planella, M. T., R. Stehberg, B. Tagle, H. Niemeyer \& C. DeL Río. 1993. La fortaleza indígena del Cerro Grande de La Compañía (valle del Cachapoal) y su relación con el proceso expansivo meridional incaico. Boletín del Museo Regional de La Araucanía 4: 403-421. Temuco.

Planella, M. T., B. Tagle, R. Stehberg \& H. Niemeyer. 2004. Logros y fracasos en la etapa de recuperación de un patrimonio arqueológico e histórico vulnerado: el caso de la fortaleza Cerro Grande de la Compañía. Chungara 36 (Volumen Especial): 1159-1174. Arica.

Prado, C. \& M. Barrientos. 2011. Aporte de la arqueología al estudio urbano de la ciudad de Santiago. El caso de la manzana de la Catedral. Revista Canto Rodado 6: 1-32. Ciudad de Panamá.

Prieto, C. \& H. Chiavazza. 2009. La producción cerámica Viluco entre los siglos xv y xviI (Provincia de Mendoza, Argentina). Chungara 41 (2): 261-274. Arica.

Quevedo, S., G. Rojas \& D. BAudet. 1999. Estudio de una colección arqueológica y su referente botánico: Los 
contenidos de los ceramios pertenecientes al cementerio incaico Las Tinjas de Quilicura. En Informes. Fondo de apoyo a la investigación patrimonial, pp. 14-20. Santiago: Dirección de Bibliotecas Archivos y Museos.

RAFFino, R. 1981. Los Inkas del Kollasuyu: origen, naturaleza $y$ transfiguraciones de la ocupación inka en los Andes meridionales. Buenos Aires: Ramos Americana Editores.

Raffino, R., L. Iácona, R. Moralejo, D. Gobbo \& M. Couso (Eds.). 2015. Una capital inka al sur del kollasuyu: El Shincal de Quimivil. Buenos Aires: Fundación de Historia Natural Félix de Azara Departamento de Ciencias Naturales y Antropológicas-CEBBAD-Instituto Superior de Investigaciones-Universidad Maimónides.

RIVAs, P. 2008 Ms. Informe final arqueología proyecto ampliación cripta Catedral metropolitana.

Rosales, D. 1877 [1647]. Historia general de reyno de Chile. Flandes indiano. Tomo I. Valparaíso: Imprenta de Valparaíso.

SaAvedra, M. \& L. Cornejo. 2015. Arqueología del Palacio de la Real Aduana (Santiago de Chile). Desde tiempos inkaicos hasta finales de la colonia española. Revista Canto Rodado 10: 97-124. Ciudad de Panama.

SÁNCHEZ, R. 2001-02. El Tawantinsuyu salvaje en el finis terrae australis (Chile Central). Revista Chilena de Antropología 16: 87-127. Santiago.

SÁnCHEZ, R. 2004. El Tawantinsuyu en Aconcagua. Chungara 36 (2): 325-336. Arica.

Sánchez, R. \& M. Massone. 1995. Cultura Aconcagua. Santiago: Dirección de Bibliotecas, Archivos y Museos de Chile-CIDBA.

SAnhueza, L. 2001. El aríbalo inca en Chile central. Revista Werkén 2: 47-69. Santiago.

SANGuinetti, N. 1975. Construcciones indígenas en el cerro Mercachas (Departamento de Los Andes, provincia de Aconcagua). Anales del Museo de Historia Natural de Valparaíso 8: 129-139. Valparaíso.

Silva, O. 1985. La expansión incaica en Chile. Problemas y reflexiones. En Actas del IX Congreso Nacional de Arqueología, pp. 321-344, Sociedad Chilena de Arqueología, Museo Arqueológico de La Serena. La Serena.

SChiffer, M. 1976. Behavioral Archeology. Nueva York: Academic Press.

SCHIfFer, M. 1983. Toward the identification of formation processes. American Antiquity 48 (4): 675-706.

Sunyer, M., X. Roda, A. Benito-Calvo, J. MartínezMoreno \& R. Mora. 2014. Verificando la integridad del registro arqueológico: análisis de fábricas en las unidades arqueológicas del paleolítico medio/superior de la Cova Gran (Santa Linya, Lleida). Treballs d'Arqueologia 20: 55-77. Barcelona.

Stehberg, R. 1976. La fortaleza de Chena y su relación con la ocupación incaica de Chile Central. Publicación Ocasional del Museo de Historia Natural 23: 3-37. Santiago.
Stehberg, R. 2006. En torno al simbolismo del pucara de Chena. Diseño urbano y paisaje 3 (9). <https://issuu. com/observatorio_panoptico/docs/9_pucara_chena $>$ [consultado 19-03-2018].

Stehberg, R. 2013. Caminos, guacas y el reducto fortificado de cerro el peral: instalaciones para el control inca del paso de Chada, Chile Central. Boletín del Museo Nacional de Historia Natural 62: 129-146. Santiago.

Stehberg, R. \& G. Sotomayor. 2012. Mapocho incaico. Boletín del Museo Nacional de Historia Natural 61: 85149. Santiago.

Troncoso. A. 2005. Hacia una semiótica del arte rupestre de la cuenca superior del río Aconcagua, Chile Central. Chungara 37 (1): 21-35. Arica.

Troncoso, A., D. Pavlovic, F. Acuto, R. Sánchez \& A. GonZÁLEZ-GARCÍA. 2012. Complejo arquitectónico cerro Mercachas: arquitectura y ritualidad incaica en Chile Central. Revista Española de Antropología Americana 42 (1): 293-319. Madrid.

Uribe, M. 1999-2000. La arqueología inka en Chile. Revista Chilena de Antropología 15: 63-97. Santiago.

VAldÉs, X. \& P. MATtA. 1986. Oficios y trabajos de las mujeres de Pomaire. Santiago: Pehuén-Centro de Estudio de la Mujer.

VÁsquez, M. 1994. Contextos cerámicos incaicos en Chile central. Arqueología de Chile Central. En Actas del $2^{\circ}$ Taller de Arqueología de Chile Central. <http://www.arqueologia. cl/actas2/vasquez.pdf $>$ [consultado 19-03-2018].

WASHBURn, D. 1983. Symetric analysis of ceramic design: two test of the method on neolithic material from Greece and the Aegean. En Structure and cognition in art, D. Eashburn Ed., pp. 138-164. Cambridge: New Direction in Archaeology, Cambrige University Press.

Williams, V. 2000. El imperio inka en la provincia de Catamarca. Intersecciones en Antropología 1 (1): 55-78. Olavarría.

Williams, V. \& T. D’Altroy. 1998. El sur del Tawantinsuyu: un dominio selectivamente intensivo. Tawantinsuyu 5: 170-178. Camberra.

Zıólkowski, M. 1996. La guerra de los Wawqi. Los objetivos y los mecanismos de la rivalidad dentro de la élite inka, siglos XV-XVI. Quito: Abya-Yala. 